NBER WORKING PAPER SERIES

\title{
REGULATORY ARBITRAGE IN TEACHER HIRING AND RETENTION: EVIDENCE FROM MASSACHUSETTS CHARTER SCHOOLS
}

\author{
Jesse M. Bruhn \\ Scott A. Imberman \\ Marcus A. Winters \\ Working Paper 27607 \\ http://www.nber.org/papers/w27607 \\ NATIONAL BUREAU OF ECONOMIC RESEARCH \\ 1050 Massachusetts Avenue \\ Cambridge, MA 02138
}

July 2020

We would like to thank Sarah Cohodes, Celeste K. Caruthers, Kevin Lang, Daniele Paserman, Raymond Fisman, participants at the Association for Education and Finance Policy Annual Conference, participants at the Annenberg Institute Half-Baked workshop, and participants at the Boston University Labor Reading Group for helpful comments, criticisms, and suggestions. We would also like to extend our gratitude to the Massachusetts Department of Elementary and Secondary Education, and especially Carrie Conaway, Matthew Deninger, Pierre Lucien, and Patrick Buckwalter, for their cooperation and support in this endeavor. Finally, we would like to acknowledge the Smith Richardson Foundation for providing the funding that made this research possible. The views expressed herein are those of the authors and do not necessarily reflect the views of the National Bureau of Economic Research.

NBER working papers are circulated for discussion and comment purposes. They have not been peer-reviewed or been subject to the review by the NBER Board of Directors that accompanies official NBER publications.

(C) 2020 by Jesse M. Bruhn, Scott A. Imberman, and Marcus A. Winters. All rights reserved. Short sections of text, not to exceed two paragraphs, may be quoted without explicit permission provided that full credit, including $\odot$ notice, is given to the source. 
Regulatory Arbitrage in Teacher Hiring and Retention: Evidence from Massachusetts Charter Schools

Jesse M. Bruhn, Scott A. Imberman, and Marcus A. Winters

NBER Working Paper No. 27607

July 2020

JEL No. I21,J45,M51

\section{ABSTRACT}

We study personnel flexibility in charter schools by exploring how teacher retention varies with teacher and school quality in Massachusetts. Charters are more likely to lose their highest and lowest value-added teachers. Low performers tend to exit public education, while high performers tend to switch to traditional public schools. To rationalize these findings, we propose a model in which educators with high fixed-costs use charter schools to explore teaching careers before obtaining licenses required for higher paying public sector jobs. The model suggests charter schools create positive externalities for traditional public schools by increasing the average quality of available teachers.

Jesse M. Bruhn

Department of Economics

Brown University

Providence, RI 02912

jesse_bruhn@brown.edu

Scott A. Imberman

Michigan State University

486 W. Circle Drive

110 Marshall-Adams Hall

East Lansing, MI 48824-1038

and NBER

imberman@msu.edu
Marcus A. Winters

Boston University

Wheelock College of Education

\& Human Development

Office 601

2 Silber Way

Boston, MA 02215

marcusw@bu.edu 


\section{Introduction}

One of the defining features of charter schools is increased flexibility in teacher employment practices. Proponents argue that this flexibility allows charter schools to better manage their human capital (Hoxby, 2002). Traditional public schools (TPS) are frequently prohibited from administrative actions that could improve the quality of their teachers such as removing and replacing low-performing teachers (Goldhaber \& Hansen, 2010; Staiger \& Rockoff, 2010; Cowen \& Winters, 2013), hiring non-certified teachers (Backes \& Hansen, 2015; Clark et al., 2013; Kane et al., 2008), and changing compensation via pay or expected work hours. In theory, this means that charter schools can improve student outcomes by finding and retaining high value-added teachers who might otherwise slip through the cracks (Ballou \& Podgursky, 1997). However, it is an open question whether, and to what extent, charter schools are able to capitalize on this comparative labor market flexibility. This question is particularly important considering the wide variation in charter school impacts found nationwide (Center for Research on Education Outcomes, 2015).

To deepen our understanding of teacher labor markets in the charter school context, we study labor mobility within and across the charter and traditional public school sectors in Massachusetts. We begin by documenting how attrition varies across the school and teacher valueadded distributions. We find that charter schools in Massachusetts are more likely to lose both their highest and lowest performing teachers relative to traditional public schools. Broadly speaking, attrition patterns in the charter sector exhibit a U-shape with respect to teacher quality as measured by value-added, while attrition in the traditional public sector is either flat or exhibits a small downward slope. While ex-ante one might suspect that higher performing charters should be better able to hold onto their high performers and more likely to lose their low performers, we find little difference in these patterns by school value-added within the charter sector. Thus, this finding appears to be a characteristic of charter schools more generally rather than a predictor of quality differences between them.

Intriguingly, where charter teachers who leave their current schools end up the following year differs by teacher value-added. Teachers that are high performing within their school tend to move to other public school employment opportunities. Teachers that are low performing within their school tend to exit the Massachusetts education system entirely. We also find that among teachers working in a charter school without a license, the decision to obtain a license predicts a sudden and permanent increase in the probability of moving to a traditional public school.

Combined, these pieces of evidence suggest that charters act as a filtering mechanism by 
inducing their worst teachers to leave the education sector while also providing a pathway for high quality teachers to enter the traditional public system. One potential explanation for this pattern is via a form of regulatory arbitrage. While traditional public schools are restricted through union rules and regulation to require an entry barrier (licensure) and pay a relatively high wage, charters are not subject to these requirements and hence are free to hire unlicensed teachers at a lower wage. This is similar to the way firms like Uber and Lyft take advantage of loopholes in taxi regulations to enter the personal transport market and pay lower wages, undercutting the highly regulated incumbent firms; however, we note that in the case of charter schools, the different regulatory structures are by the design of policy rather than the result firms searching for loopholes. The main difference between the market for taxis and the market for students is that charters are also often restricted in supply. For example, Massachusetts has a strict cap on the number of charters. Thus the incumbent firms are able to continue offering higher wages, and potential teachers can use the charter system to learn about their taste for teaching before committing to the fixed cost of licensure.

To capture this intuition, we develop a simple model of regulatory arbitrage in the education sector. In the model, charter schools may hire licensed or unlicensed teachers at a wage of their choosing. Traditional public schools have perfectly inelastic demand for licensed teachers and are required by law to pay an exogenously determined wage. Teachers have a heterogeneous taste for teaching, but may pay to learn their type by attaining licensure through a teacher preparation program. Once hired in the charter sector, unlicensed teachers learn their type and re-optimize.

The model delivers predictions that are consistent with our data. Provided there is a heterogeneous cost of licensure, charter schools hire unlicensed teachers and have high attrition relative to traditional public schools. Low value-added charter school teachers will exit the profession. High value-added charter school teachers will obtain licensure and switch to traditional public schools. A novel implication of the model is that it suggests the potential for charter schools to create a positive externality on traditional public schools even in the absence of competitive effects by increasing the average quality of available teacher labor.

Our key empirical challenge in this paper is to generate state wide estimates of teacher and school value-added. While there is high-quality, lottery-based evidence that value-added models perform well within large urban school districts (Kane \& Staiger, 2008; Chetty et al., 2014a; Deming, 2014; Bacher-Hicks et al., 2014; Koedel et al., 2015; Angrist et al., 2017), recent work has documented that sorting can complicate the interpretation of test score gains even in the presence of random assignment (Bruhn, 2019). There is also substantial evidence documenting the importance of school-level inputs within the charter school sector for generating 
test score gains (Angrist et al., 2013; Dobbie \& Fryer, 2013) and a small body of evidence arguing that teacher-school match effects are important drivers of value-added (Jackson, 2013). Standard value-added models will conflate the impact of these school-level inputs and other sectoral differences with teacher value-added. This may lead to spurious statistical relations when we subsequently predict teacher turnover as a function of test score gains. For example, if a no-excuses discipline philosophy generates large benefits for students but decreases job satisfaction for teachers, we risk conflating the effect of no-excuses on test score gains with effects on attrition.

We address this challenge by estimating mutually consistent measures of school valueadded and within school teacher value-added via a correlated random effects model. This approach effectively attributes all cross-school variation in test score gains to schools. While this has the drawback that we are unable to interpret our teacher estimates as reflecting a global distribution of teacher value-added, it does allow us to address the question of whether charter schools differentially remove their own worst teachers under relatively weak assumptions. We validate our model by comparing the results from our method with results from the charter school literature based on lotteries in Boston (Angrist et al., 2013; Cohodes et al., 2018). Our model broadly replicates key empirical patterns from existing work.

This paper builds on the intersection of two rich literatures. The first is work on how teacher quality and working conditions affect teacher labor market decisions. Mostly this research has focused on how teachers move within the traditional public school system (Feng \& Sass, 2017; Jackson, 2012; Strunk, 2011; Kukla-Acevedo, 2009; Feng, 2010). Of particular importance is Loeb et al. (2012) which uses data from a large Florida school district and a similar empirical strategy to estimate the relation between school value-added, teacher value-added, and attrition. They find that more effective schools are better able to retain higher quality teachers, but not able to differentially remove ineffective teachers. Our findings in the public sector are broadly consistent with their work. Our study also helps us better understand the underlying mechanisms for charter school impacts on student performance (Cohodes et al., 2018; Clark et al., 2015; Angrist et al., 2013; Dobbie \& Fryer, 2013; Abdulkadiroglu et al., 2011; Imberman, 2011a; Booker et al., 2007; Bifulco \& Ladd, 2006; Sass, 2006). The studies by Cohodes et al. (2018), Angrist et al. (2013), and Abdulkadiroglu et al. (2011) are particularly relevant as we study the same context - charter schools in Massachusetts - and they find considerable variation in charter school impacts.

There is considerably less work on the overlap in the literature that looks at teacher mobility and teacher quality in charter schools and how charter schools impact the teacher labor market. For example, Baker \& Dickerson (2006) find that charter schools tend to hire from more com- 
petitive undergraduate institutions than traditional public schools. Stuit \& Smith (2012) show that charter schools have turnover rates that are twice as high as for traditional public schools and that this is correlated with higher proportions of inexperienced and uncertified teachers along with lower unionization rates. Further, Carruthers (2012) finds that less qualified and less effective teachers tend to move from traditional public schools to charter schools. Jabbar et al. (2019) present qualitative evidence that licensure requirements and other regulations serve as a meaningful barrier keeping charter school teachers from entering the public school workforce. Jackson (2012) finds some empirical support for a model for traditional public school teachers career decisions that focuses on teachers determining whether to move into the charter sector and predicts that public school administrators will respond by increasing teachers salaries. We build upon this literature by analyzing attrition and the relationship between mobility and quality in both the the traditional public and charter sectors, and by introducing the idea that their regulatory freedom allows charter schools to draw teachers that otherwise would not have entered traditional public schools.

Our study is closest to Cowen \& Winters (2013) who look at teacher attrition in Florida charter schools. They generally find that, while overall attrition is higher in charter schools, there is little difference between charter and traditional public schools in terms of how this attrition varies with teacher quality. These results suggest that charter schools are unable to take advantage of weaker employment protections to remove low-performing and retain highperforming teachers. However, a key disadvantage of this study is that charter schools in Florida tend to be low performing relative to charter schools in other states (Center for Research on Education Outcomes, 2009). Hence, it is possible that the results could differ in a higher performing charter school environment. Massachusetts is thus an ideal context to test this theory as there is a large amount of evidence indicating that their charter schools are particularly effective. Indeed, our findings differ considerably from those in Cowen \& Winters (2013) as we find large differences in attrition both at the top and bottom of schools' teacher quality distributions. These generate new and novel implications for the way charter schools manage their human capital, and how this interacts with the quality of the educator labor force as a whole.

\section{Measuring Test Score Gains and Teacher Attrition}

We use data from the Massachusetts Department of Elementary and Secondary Education (DESE) to estimate teacher and school value-added at the state wide level. In Section 2.1, we describe the data and provide summary statistics for students and teachers. In Section 2.2 
we describe our approach to estimating value-added.

\subsection{The Universe of Administrative Student and Teacher Records}

This paper uses data on the universe of public school students and their teachers as provided by DESE. Student-level demographic and socioeconomic variables come from Student Information Management System (SIMS) data spanning academic years 2008-2009 through 2016-2017. Student test scores in math and English language arts (ELA) come from Massachusetts Comprehensive Assessment System (MCAS) data spanning academic years 20082009 through 2016-2017. Teacher-level variables, including school-level assignments necessary to determine transitions, come from Education Personnel Information Management System (EPIMS) data spanning academic years 2008-2009 through 2016-2017. Information on student and teacher classroom assignments necessary to link students with their teachers comes from Student Course Schedule (SCS) data spanning academic years 2011-2012 through 20162017. For a detailed description of the data cleaning process for each of these individual data sets prior to linking, see Appendix A.

\section{Sample Construction}

In order to estimate teacher value-added, we need to link student-year observations to both their test scores and the educator primarily responsible for teaching the relevant content area to that student. To accomplish this task, we filter the SCS data to only include courses with state-level codes indicating math and ELA content instruction. For primary school grades, we also keep nondifferentiated courses that cover all content instruction. We then link these student-yearcourse level observations to the EPIMS data by Massachusetts Educational Personnel Identifier (MEPID), year, district, school, course, section, and term of instruction. We fail to match $1.9 \%$ of student-course-year observations to any educational staff in the EPIMS data. We drop these observations. We then restrict the sample to observations where the staff assigned to the course has a job assignment classified as "Teacher" or "Co-teacher." We also restrict the data to class assignments designated as "Core Subject." This effectively removes supporting staff and specialists from the data. From there, we merge in student demographic characteristics from SIMS using the State Assigned Student Identifier (SASID), year, and school district. Approximately $1.6 \%$ of the sample of student-course-year observations do not have a corresponding student match in the SIMS data. The vast majority of these matching failures occur in 2011, which is the first year the state tracked student coursework. In all other years, the nonmatch rates are less than $0.1 \%$. We drop the unmatched observations. We then drop observations that correspond 
to courses taught in alternative education programs and courses taught prior to third grade. ${ }^{1}$ To find a student's assigned math (ELA) teacher, we look within nondifferentiated and math (ELA) courses at the student-year level. Where we find only one teacher, we consider that to be the student's primary math teacher. When we find multiple teachers, we drop the student from the sample for that year. ${ }^{2}$ Finally, we merge in math and ELA test scores from the MCAS data at the student-year level. ${ }^{3}$

After matching students to distinct math and ELA teachers, we apply a few additional student-level sample restrictions. Since we wish to control for lagged test scores when estimating value-added, we drop observations that are missing test scores from the previous year. Note that this removes students in Grade 3 and below, since that is the year when state standardized testing begins. We also drop students in Grade 9 and above. This restriction is necessary because highschool students typically have multiple content area instructors, so it is difficult to pair students with distinct math/ELA teachers. We also drop students who took alternative assessments.

Next we apply several sample restrictions at the classroom level similar to those employed in Chetty et al. (2014b). Specifically, we drop students that appear in classrooms with less than 10 or more than 50 students, as well as the classrooms of teachers linked to more than 200 students in a given year. The first condition is necessary to ensure the classroom level sample size is sufficient for value-added estimation. The second two conditions likely reflect measurement error in the data. In practice, these restrictions cause us to lose less than $1 \%$ of student-year observations. We also drop students in classrooms where more than $25 \%$ of students are classified as having a nonspecific learning related disability. This leads us to lose $7 \%$ of the remaining student-year observations. We then drop students that attend school on an island, which leads us to lose less than $1 \%$ of student-year observations. ${ }^{4}$ The final data set contains 620,516 distinct student-level observations across 1,327 traditional public schools

\footnotetext{
${ }^{1}$ We impose these restrictions here to facilitate merging in the MCAS data, since the state standardized testing begins in third grade. We will later restrict the sample to grades 4-8 for the purposes of value added estimation, since these are the grades where it is generally possible to find both a lagged test score and distinct math and ELA teachers for the majority of students.

${ }^{2}$ Ten percent of student-year observations are dropped due to multiple, subject-specific teacher matches within a given year. However, we note that only $2.6 \%$ of students are dropped from the data entirely as a result of this restriction, and that the distribution of drops skews towards later grades (when multi-teacher assignment patterns are more common).

${ }^{3}$ Prior to merging, we standardize test scores at the year, grade, subject, and test-type level to have mean 0 and standard deviation 1. See Appendix A for more details.

${ }^{4}$ The school fixed-effects of students who attend school on an island is not identified given our large set of preferred controls. These schools are quite small, and there is not enough student switching between the islands and the mainland over this time period.
} 
and 65 charter schools. $^{5}$

\section{Summary Statistics}

Table 1 provides summary statistics for the students in our sample. At the bottom of the table, observation counts for schools, students, and student-years are provided but means are calculated at the student-year level. Columns divide the sample into charter and traditional public schools. We also subdivide schools by whether they fall above or below the median of the within-sector school value added distribution. "Math" and "ELA" refer to math and English language arts standardized test scores. Note that because we standardize test scores prior to imposing sample restrictions, the averages in table 1 are not zero. "Subsidized lunch" refers to students who receive free or reduced price lunch. "Any disability" refers to students who have been diagnosed with at least one of the 13 official disability categories tracked by the state. "Limited English" refers to students who are classified as English Language Learners (ELs).

In our analysis sample, charter schools serve a more diverse, lower socioeconomic status (SES), and lower performing student population than their traditional public school peers. However, it is important to note that these differences largely reflect selection into neighborhoods on the part of the Massachusetts charter schools, which disproportionately operate in poorer, more urban areas (Angrist et al., 2013). Even so, within the charter sector, high valueadded charter schools serve a student population that is disproportionately low-SES relative to high value-added schools whereas the opposite relation holds among traditional public schools. Students in high value-added charter schools are $20 \%$ more likely to receive a subsidized lunch, $28 \%$ more likely to be black, and $7 \%$ more likely to be Hispanic than those in low value-added charters. Among traditional public schools, students in high value-added institutions serve a population that is $22 \%$ less likely to receive a subsidized lunch, $2 \%$ less likely to be black, and $11 \%$ less likely to be Hispanic. It is also worth noting that achievement is higher in the high value-added schools than in the low value-added schools. While this is partly by construction, the gap is nonetheless interesting in the case of the charters given their more disadvantaged student profile. ${ }^{7}$

Table 2 provides summary statistics for teachers. "Attrit" refers to a teacher who was employed in a given school at time $t$ and is no longer employed in that school at time $t+1$. Thus teachers who attrit have either moved across schools within Massachusetts or they no

\footnotetext{
${ }^{5}$ Without applying any restrictions, there are 1,709 traditional public schools and 83 charter schools.

${ }^{6}$ See Section 2.2 for details on the school value-added model

${ }^{7} \mathrm{We}$ standardize the achievement scores prior to restricting our sample. As a result there is some positive selection in the sample restrictions which leads average standardized achievement to be above zero.
} 
TABLE 1: Summary Statistics: Students

\begin{tabular}{|c|c|c|c|c|c|c|}
\hline & \multicolumn{3}{|c|}{ Charter schools } & \multicolumn{3}{|c|}{ Traditional public schools } \\
\hline & All & School VA $>$ Median & School VA $<$ Median & All & School VA > Median & School VA $<$ Median \\
\hline Math & $\begin{array}{l}0.14 \sigma \\
(0.88)\end{array}$ & $\begin{array}{l}0.21 \sigma \\
(0.86)\end{array}$ & $\begin{array}{l}0.08 \sigma \\
(0.89)\end{array}$ & $\begin{array}{l}0.17 \sigma \\
(0.92)\end{array}$ & $\begin{array}{l}0.38 \sigma \\
(0.85)\end{array}$ & $\begin{array}{c}-0.02 \sigma \\
(0.94)\end{array}$ \\
\hline ELA & $\begin{array}{l}0.08 \sigma \\
(0.86)\end{array}$ & $\begin{array}{l}0.11 \sigma \\
(0.85)\end{array}$ & $\begin{array}{l}0.05 \sigma \\
(0.86)\end{array}$ & $\begin{array}{l}0.17 \sigma \\
(0.89)\end{array}$ & $\begin{array}{l}0.36 \sigma \\
(0.82)\end{array}$ & $\begin{array}{c}0 \sigma \\
(0.92)\end{array}$ \\
\hline Female & $\begin{array}{l}52 \% \\
(50)\end{array}$ & $\begin{array}{l}52 \% \\
(50)\end{array}$ & $\begin{array}{l}52 \% \\
(50)\end{array}$ & $\begin{array}{l}50 \% \\
(50)\end{array}$ & $\begin{array}{l}50 \% \\
(50)\end{array}$ & $\begin{array}{l}50 \% \\
(50)\end{array}$ \\
\hline White & $\begin{array}{l}63 \% \\
(48)\end{array}$ & $\begin{array}{l}47 \% \\
(50)\end{array}$ & $\begin{array}{l}77 \% \\
(42)\end{array}$ & $\begin{array}{l}85 \% \\
(36)\end{array}$ & $\begin{array}{l}85 \% \\
(36)\end{array}$ & $\begin{array}{l}85 \% \\
(36)\end{array}$ \\
\hline Black & $\begin{array}{l}32 \% \\
(47)\end{array}$ & $\begin{array}{l}47 \% \\
(50)\end{array}$ & $\begin{array}{l}19 \% \\
(39)\end{array}$ & $\begin{array}{l}10 \% \\
(30)\end{array}$ & $\begin{array}{l}9 \% \\
(28)\end{array}$ & $\begin{array}{l}11 \% \\
(31)\end{array}$ \\
\hline Hispanic & $\begin{array}{l}25 \% \\
(43)\end{array}$ & $\begin{array}{l}32 \% \\
(47)\end{array}$ & $\begin{array}{l}20 \% \\
(40)\end{array}$ & $\begin{array}{l}14 \% \\
(34)\end{array}$ & $\begin{array}{l}8 \% \\
(26)\end{array}$ & $\begin{array}{l}19 \% \\
(39)\end{array}$ \\
\hline Subsidized lunch & $\begin{array}{l}50 \% \\
(50)\end{array}$ & $\begin{array}{l}61 \% \\
(49)\end{array}$ & $\begin{array}{l}41 \% \\
(49)\end{array}$ & $\begin{array}{l}33 \% \\
(47)\end{array}$ & $\begin{array}{l}21 \% \\
(41)\end{array}$ & $\begin{array}{l}43 \% \\
(50)\end{array}$ \\
\hline Any disability & $\begin{array}{l}14 \% \\
(34)\end{array}$ & $\begin{array}{l}14 \% \\
(35)\end{array}$ & $\begin{array}{l}13 \% \\
(34)\end{array}$ & $\begin{array}{l}14 \% \\
(35)\end{array}$ & $\begin{array}{l}14 \% \\
(35)\end{array}$ & $\begin{array}{l}13 \% \\
(34)\end{array}$ \\
\hline Limited English & $\begin{array}{l}5 \% \\
(22)\end{array}$ & $\begin{array}{l}8 \% \\
(28)\end{array}$ & $\begin{array}{l}2 \% \\
(15)\end{array}$ & $\begin{array}{l}5 \% \\
(21)\end{array}$ & $\begin{array}{l}3 \% \\
(18)\end{array}$ & $\begin{array}{l}6 \% \\
(24)\end{array}$ \\
\hline Observations & 62,888 & 29,020 & 33,868 & $1,517,038$ & 680,573 & 836,465 \\
\hline Observations (students) & 30,374 & 14,980 & 15,554 & 590,142 & 319,598 & 374,249 \\
\hline Schools & 65 & 33 & 32 & 1,327 & 664 & 663 \\
\hline
\end{tabular}

Note: This table presents summary statistics for the full sample of students used to estimate value-added. "School VA > Median" refers to schools within the given sector that are above median quality according to our school value-added model (see Section 2.2 for estimation details). "Math" and "ELA" refer to math and English language arts standardized test scores. "Subsidized lunch" refers to students who receive free or reduced price lunch. "Any Disability" refers to students who have been diagnosed with one of 13 official disability categories tracked by the state. "Limited English" refers to students who are classified as English Language Learners. Statistics are calculated at the student-year level. Standard deviations are reported in parentheses. 
TABLE 2: Summary Statistics: Teachers

\begin{tabular}{ccccc}
\hline \hline \multirow{2}{*}{ Charter } & TPS & Charter & TPS \\
\hline \multirow{2}{*}{ Years in district } & 4.51 & 10.08 & 4.44 & 10.21 \\
& $(430)$ & $(798)$ & $(431)$ & $(802)$ \\
Female & $74 \%$ & $83 \%$ & $83 \%$ & $86 \%$ \\
& $(44)$ & $(38)$ & $(37)$ & $(34)$ \\
White & $90 \%$ & $96 \%$ & $93 \%$ & $96 \%$ \\
& $(30)$ & $(20)$ & $(26)$ & $(19)$ \\
Black & $7 \%$ & $3 \%$ & $6 \%$ & $3 \%$ \\
& $(25)$ & $(17)$ & $(24)$ & $(17)$ \\
Hispanic & $3 \%$ & $2 \%$ & $2 \%$ & $2 \%$ \\
& $(16)$ & $(14)$ & $(14)$ & $(13)$ \\
Licensed & $80 \%$ & $98 \%$ & $82 \%$ & $98 \%$ \\
& $(40)$ & $(14)$ & $(38)$ & $(13)$ \\
Attrit & $22 \%$ & $14 \%$ & $23 \%$ & $14 \%$ \\
& $(42)$ & $(35)$ & $(42)$ & $(35)$ \\
TPS move & $11 \%$ & $9 \%$ & $12 \%$ & $9 \%$ \\
& $(31)$ & $(28)$ & $(32)$ & $(28)$ \\
Charter move & $2 \%$ & $0 \%$ & $3 \%$ & $0 \%$ \\
& $(16)$ & $(5)$ & $(16)$ & $(5)$ \\
Exit & $9 \%$ & $5 \%$ & $9 \%$ & $5 \%$ \\
& $(29)$ & $(22)$ & $(28)$ & $(22)$ \\
Observations & 3,836 & 93,448 & 3,666 & 97,202 \\
& 1,065 & 13,332 & 1,026 & 13,920 \\
\hline \multirow{2}{*}{ Observations (teachers) } & & & &
\end{tabular}

Note: This table presents summary statistics for the full sample of teachers we used to estimate value-added. "Years in district" refers to the number of years between a teacher's hire date in the current district and the present year. "Licensed" takes a value of one if a teacher is assigned a license number in year $t$. "Attrit" refers to a teacher who was employed in a given school at time $t$ and is no longer employed in that school at time $t+1$. "TPS move" refers to teachers who have attrited and appear in a traditional public school in year $t+1$. "Charter move" refers to teachers who have attrited and appear in a charter school in year $t+1$. "Exit" refers to teachers who attrited and are no longer employed as a teacher in the education system (traditional public or charter school) in Massachusetts in year $t+1$. Standard deviations are reported in parentheses. 
longer work in the public education system in Massachusetts in year $t+1$. "TPS move" refers to teachers who have attrited and appear in a traditional public school in year $t+1$. "Charter move" refers to teachers who have attrited and appear in a charter school in year $t+1$. "Exit" refers to teachers who attrited and are no longer employed as a teacher in the education system (traditional public or charter school) in Massachusetts in year $t+1$. "Licensed" is an indicator for whether the teacher had a license at time $t$.

Charter school teachers attrit at substantially higher rates than their traditional public school counterparts. In practice, overall this attrition is roughly split evenly between teachers moving jobs within the Massachusetts public education labor force and exiting the system, though both exits and moves are more common in charters. In the charter sector, in a given year, $22 \%$ of the teacher workforce turns over: $10 \%$ leave the system entirely, and most of the rest move to traditional public schools. However, a small but non-zero portion of charter attrition reflects movement between charters $(2 \%)$. At the same time, teachers moving from traditional public schools to charter schools are nearly non-existent.

Also notable are the licensure disparities between teachers in charter and traditional public schools. Not surprisingly, virtually all TPS teachers are licensed. ${ }^{8}$ In charter schools, while most teachers are licensed, it is not required. Charter teachers are required to pass the Massachusetts licensure exam during their first year in teaching, but they are not required to have completed the requisite teacher preparatory coursework and hence can teach with any fouryear college degree. ${ }^{9}$ This bears out in the summary statistics. While $98 \%$ of math and ELA teachers in TPS have licenses, only $80 \%$ of math and $82 \%$ of ELA teachers in charters are licensed.

Table 3 describes how teacher licensure and attrition patterns vary with in-district experience. As expected, teacher licensure in charter schools is particularly low in early career teachers. Only $75 \%$ of teachers with 3 or fewer years of experience are licensed. Teachers at this experience level are also the largest group of teachers in charters. Hence, there are a large number of teachers who potentially are using charters as a stepping stone to TPS teaching. Not surprising, with the exception of teachers in charters with 16 or more years of experience - a very small group - teachers with little experience are also more likely to move to TPS or exit teaching entirely.

\footnotetext{
${ }^{8} \mathrm{~A}$ small percentage of teachers in the TPS are provided temporary waivers.

${ }^{9} \mathrm{An}$ exception is English as a second language teachers who do require licensure. http://www.doe.mass.edu/charter/guidance/2017-1.html
} 
TABLE 3: Teacher Attrition and Licensure Profiles

\begin{tabular}{|c|c|c|c|c|c|c|c|c|c|c|c|c|}
\hline \multirow[b]{2}{*}{ Years in district } & \multicolumn{6}{|c|}{ Charter school } & \multicolumn{6}{|c|}{ Traditional public school } \\
\hline & $1-3$ & $4-6$ & $7-9$ & $10-12$ & $13-15$ & $16-29$ & $1-3$ & $4-6$ & $7-9$ & $10-12$ & $13-15$ & $16-29$ \\
\hline Licensed & $\begin{array}{l}76.1 \% \\
(42.7)\end{array}$ & $\begin{array}{l}82.9 \% \\
(37.6)\end{array}$ & $\begin{array}{l}86.5 \% \\
(34.2)\end{array}$ & $\begin{array}{l}86.1 \% \\
(34.6)\end{array}$ & $\begin{array}{c}92 \% \\
(27.2)\end{array}$ & $\begin{array}{l}96.8 \% \\
(17.7)\end{array}$ & $\begin{array}{l}94.8 \% \\
(22.2)\end{array}$ & $\begin{array}{l}98.3 \% \\
(12.8)\end{array}$ & $\begin{array}{c}99.1 \% \\
(9.4)\end{array}$ & $\begin{array}{c}99.5 \% \\
(7.4)\end{array}$ & $\begin{array}{c}99.6 \% \\
(6.2)\end{array}$ & $\begin{array}{c}99.8 \% \\
(4.4)\end{array}$ \\
\hline Attrit & $\begin{array}{l}25 \% \\
(43.3)\end{array}$ & $\begin{array}{l}21.4 \% \\
(41.1)\end{array}$ & $\begin{array}{c}13 \% \\
(33.6)\end{array}$ & $\begin{array}{l}13.4 \% \\
(34.1)\end{array}$ & $\begin{array}{l}8.4 \% \\
(27.8)\end{array}$ & $\begin{array}{l}34.6 \% \\
(47.7)\end{array}$ & $\begin{array}{l}22.4 \% \\
(41.7)\end{array}$ & $\begin{array}{l}13.8 \% \\
(34.5)\end{array}$ & $\begin{array}{l}11.4 \% \\
(31.8)\end{array}$ & $\begin{array}{l}9.5 \% \\
(29.3)\end{array}$ & $\begin{array}{l}8.7 \% \\
(28.2)\end{array}$ & $\begin{array}{l}10.2 \% \\
(30.2)\end{array}$ \\
\hline Move & $\begin{array}{l}14.7 \% \\
(35.4)\end{array}$ & $\begin{array}{l}11.2 \% \\
(31.5)\end{array}$ & $\begin{array}{l}7.5 \% \\
(26.4)\end{array}$ & $\begin{array}{l}6.9 \% \\
(25.4)\end{array}$ & $\begin{array}{c}6.1 \% \\
(24)\end{array}$ & $\begin{array}{c}30.1 \% \\
(46)\end{array}$ & $\begin{array}{l}15.7 \% \\
(36.4)\end{array}$ & $\begin{array}{l}8.8 \% \\
(28.4)\end{array}$ & $\begin{array}{l}6.9 \% \\
(25.4)\end{array}$ & $\begin{array}{c}6.2 \% \\
(24)\end{array}$ & $\begin{array}{l}5.7 \% \\
(23.2)\end{array}$ & $\begin{array}{l}5.1 \% \\
(21.9)\end{array}$ \\
\hline TPS move & $\begin{array}{l}10.8 \% \\
(31.1)\end{array}$ & $\begin{array}{l}9.6 \% \\
(29.5)\end{array}$ & $\begin{array}{l}6.3 \% \\
(24.3)\end{array}$ & $\begin{array}{l}6.2 \% \\
(24.1)\end{array}$ & $\begin{array}{c}4.6 \% \\
(21)\end{array}$ & $\begin{array}{l}28.6 \% \\
(45.3)\end{array}$ & $\begin{array}{c}15 \% \\
(35.7)\end{array}$ & $\begin{array}{l}8.6 \% \\
(28.1)\end{array}$ & $\begin{array}{l}6.8 \% \\
(25.2)\end{array}$ & $\begin{array}{c}6 \% \\
(23.8)\end{array}$ & $\begin{array}{l}5.6 \% \\
(23.1)\end{array}$ & $\begin{array}{c}5 \% \\
(21.8)\end{array}$ \\
\hline Charter move & $\begin{array}{l}3.9 \% \\
(19.3)\end{array}$ & $\begin{array}{l}1.6 \% \\
(12.4)\end{array}$ & $\begin{array}{l}1.2 \% \\
(11)\end{array}$ & $\begin{array}{l}0.7 \% \\
(8.5)\end{array}$ & $\begin{array}{l}1.5 \% \\
(12.3)\end{array}$ & $\begin{array}{l}1.5 \% \\
(12.2)\end{array}$ & $\begin{array}{l}0.8 \% \\
(8.9)\end{array}$ & $\begin{array}{l}0.2 \% \\
(4.2)\end{array}$ & $\begin{array}{l}0.1 \% \\
(3.4)\end{array}$ & $\begin{array}{l}0.1 \% \\
(3.4)\end{array}$ & $\begin{array}{l}0.1 \% \\
(2.8)\end{array}$ & $\begin{array}{l}0.1 \% \\
(2.7)\end{array}$ \\
\hline Exit & $\begin{array}{l}10.2 \% \\
(30.3)\end{array}$ & $\begin{array}{l}10.3 \% \\
(30.4)\end{array}$ & $\begin{array}{l}5.5 \% \\
(22.8)\end{array}$ & $\begin{array}{l}6.5 \% \\
(24.7)\end{array}$ & $\begin{array}{c}2.3 \% \\
(15)\end{array}$ & $\begin{array}{l}4.5 \% \\
(20.8)\end{array}$ & $\begin{array}{l}6.7 \% \\
(24.9)\end{array}$ & $\begin{array}{c}5 \% \\
(21.7)\end{array}$ & $\begin{array}{l}4.5 \% \\
(20.7)\end{array}$ & $\begin{array}{c}3.3 \% \\
(17.9)\end{array}$ & $\begin{array}{c}3 \% \\
(17.1)\end{array}$ & $\begin{array}{c}5.1 \% \\
(22)\end{array}$ \\
\hline Observations (teachers) & 1,420 & 605 & 275 & 161 & 64 & 66 & 10,484 & 8,591 & 7,762 & 6,544 & 5,190 & 5,007 \\
\hline
\end{tabular}

Note: This table describes how teacher licensure and attrition patterns vary with time-in-district. "Years in district" refers the number of years between a teacher's hire date in the current district and the present year. "Licensed" takes a value of one if a teacher is assigned a license number in year $t$. "Attrit" refers to a teacher who was employed in a given school at time $t$ and is no longe employed in that school at time $t+1$. "TPS move" refers to teachers who have attrited and appear in a traditional public school in year $t+1$. "Charter move" refers to teachers who have attrited and appear in a charter school in year $t+1$. "Exit" refers to teachers who attrited and are no longer employed as a teacher in the education system (traditional public or charter school) in Massachusetts in year $t+1$. Standard deviations are reported in parentheses. 


\subsection{Estimating School and Teacher Value Added}

Estimating the relation between teacher value-added and attrition poses a significant technical challenge. At issue is whether, and to what degree, cross-school variation in test score gains should be attributed to teachers versus the schools themselves. If schools have different resource levels or otherwise determine policy variables such as educational curricula or discipline philosophy, off the shelf value-added models will attribute these school-level differences to underlying teacher value added. This could lead to a spurious relationship when comparing attrition rates across sectors. For example, if a no excuses discipline philosophy is highly effective at educating students while also decreasing teacher job satisfaction, we would expect to find a differential relationship between value-added and attrition across sectors even when there are no differences in the underlying attributes that contribute to test score gains at the teacher level. At the same time, we also want to see the extent to which attrition patterns with respect to teacher value-added vary with school quality. While there are potentially many useful notions of school quality, school value-added is conceptually straightforward and has been frequently employed in prior work (e.g., Loeb et al., 2012; Cowen \& Winters, 2013; Angrist et al., 2017; Bruhn, 2019). Thus we would like to employ an estimation procedure that estimates school and teacher-value added in a mutually consistent way.

To address this, we add some nuance to the empirical question we are trying to answer. Rather than attempting to learn whether charters tend to lose high-or low-VA teachers in a global sense, we ask whether charters are more likely to lose their own higher and lower VA teachers than public schools. Thus we take the existing teacher quality distribution in a school as a given and look at attrition patterns relative to the average teacher in that school.

Our baseline approach estimates value-added using a correlated teacher random effects model with a fixed school effect. This model generates mutually consistent measures of school and teacher value-added by attributing all cross-school variation in test score gains to schools. The drawback of this model is that the teacher value-added is identified relative to other teachers in the same school. Thus, the resulting teacher value-added estimates do not tell us about the global value-added distribution; that is, we can only compare value-added of two teachers relative to the average teacher in their respective schools. However, the assumptions necessary to identify the global distribution of value-added for both teachers and schools state-wide are quite strong. In particular, identifying the global distribution requires both that teachers are conditionally randomly assigned to classrooms, and that school-level inputs to educational production do not affect test score gains. Recent research has demonstrated that school level educational inputs, and in particular the practices favored by charter schools in Massachusetts, are predictive of test score gains (Angrist et al., 2013; Dobbie \& Fryer, 2013). Further, Cohodes 
et al. (2018) provide evidence which suggests that Boston charter schools may be successful precisely because they compress the value-added distribution by taking important policy variables out of the hands of teachers.

At a more conceptual level, the lack of employment protections in the charter sector adds a policy lever which is pulled by individual schools, not the state-level administration. Removing teachers will only improve student outcomes if the teachers being removed have lower global value-added than the expected global value-added of the replacement teacher the school will go on to hire. If schools differ in their ability to hire teachers that rank highly in the global valueadded distribution, our approach will (correctly) consider this as a causal effect emerging from the school itself. Ultimately, the authority to initiate removal of a teacher is housed at the level of the school administration; thus, the relevant margin for attrition is where the teacher falls relative to the average teacher in that school. This is precisely what is captured by our baseline model.

We estimate our school and teacher value-added measures in two steps using a procedure that is similar to Chetty et al. (2014b). First, we construct within-teacher test score residuals to purge the standardized tests of selection on observables. Next, we estimate a correlated random effects model with a fixed school component. The school fixed effect from this model will give us an unbiased estimate of school value-added provided students are conditionally randomly assigned to schools. Prior work has shown that school fixed effects, while biassed, do a reasonable job of approximating lottery-identified test score gains within large urban districts (Angrist et al., 2017; Deming, 2014). The teacher random effect will give us a consistent estimate of within-school teacher value-added provided students are conditionally randomly assigned to teachers within the school. While these assumptions are strong, they are still strictly weaker than what is typically required for consistent estimation of teacher value-added when the global distribution is the object of interest. Further, there is a large literature documenting that observational value-added methods appear to be forecast unbiased within large urban districts (Kane \& Staiger, 2008; Chetty et al., 2014a; Bacher-Hicks et al., 2014; Koedel et al., 2015).

\section{The Value-Added Model}

To construct test score residuals, we regress the test score $y_{i j s t}$ of student $i$ assigned to teacher $j$ at school $s$ in year $t$ on a school-by-teacher fixed effect $\delta_{j s}$ and a vector of controls $X_{i s t}$ as follows:

$$
y_{i j s t}=\delta_{j s}+\rho X_{i s t}+\epsilon_{i j s t}
$$


Our baseline control vector $X_{i s t}$ is similar to Chetty et al. (2014b). It contains a third order polynomial in lagged test scores interacted with current student grade; a third order polynomial in lagged school-by-grade level average test scores interacted with current grade; fixed effects for year and city of residence; indicators for race, ethnicity, gender, any disability, subsidized lunch recipiency, and limited English proficiency; class and school-level averages in these demographic characteristics; class size; indicators for the type of test ${ }^{10}$ as well as the type of the lagged test; and indicators for missing average test score values in the school-level averages that emerge as a result of the school not containing the relevant grade. ${ }^{11}$

Next, we construct test score residuals leaving in the fixed teacher component:

$$
\tilde{y}_{i j s t}=y_{i j s t}-\hat{\rho} X_{i s t} \approx \delta_{j s}+\epsilon_{i j s t}
$$

From there, we estimate a teacher value-added model of the following form:

$$
\tilde{y}_{i j s t}=\omega_{s}+\delta_{j s}+u_{i j s t}
$$

Where $\omega_{s}$ is a school fixed effect and $\delta_{j s}$ is a teacher-by-school random effect. From this model, we extract our school value-added measure $\hat{\omega}_{s}$ and our within-school teacher valueadded measure $\hat{\delta}_{j s}$. Note that we could equivalently calculate the within-school teacher valueadded measure directly as:

$$
\hat{\delta}_{j s}=\hat{\alpha}_{j s}\left(\tilde{\delta}_{j s}-\hat{\omega}_{s}\right)
$$

Where $\tilde{\delta}_{j s}$ is a teacher fixed effect and $\hat{\alpha}_{j s}$ is an empirical-Bayes weight that reduces variance by shrinking noisy observations toward 0 .

Shrinkage estimators of this form are standard in the value-added literature. Their purpose is to reduce the variance of value-added estimates for teachers who do not have a long teaching history at the expense of possibly introducing some bias into the point estimate for any individual teacher (Bacher-Hicks et al., 2014; Cohodes et al., 2018; Koedel et al., 2015). Provided we care about mean squared error over the collection of value-added estimates, and not just the point estimate for one or two specific teachers, which is the case in this analysis, estimates using shrinkage will be closer to the true parameter values on average than their Maximum

\footnotetext{
${ }^{10}$ Massachusetts Comprehensive Assessment System (MCAS) or Partnership for Assessment of Readiness for College and Careers (PARCC)

${ }^{11}$ For example, some middle schools in our data contain Grades 7-8, while others run from Grade 6-8. For a school that runs from Grade 7-8, we assign the Grade 6 school-average math score variable a value of 0 , and give the school a value of 1 for the Grade 6 school-average math missing-ness indicator.
} 
Likelihood counterparts (Stein, 1956; Efron, 2010).

In appendix B, we validate our method by showing that our model replicates key empirical facts from the literature on charter schools in Massachusetts. Notably, our estimates are consistent with the lottery based findings from Angrist et al. (2013) which show that Boston schools generate larger test score gains than their public school counterparts within the city; however, outside of Boston, charter schools show little advantage in math and even value-added that is slightly lower than traditional public schools. Our preferred model also exhibits patterns in the variance of teacher effects that are broadly consistent with the findings of Cohodes et al. (2018) that charter school teacher value-added is less variable than the value-added of their public school peers.

\section{Comparing Attrition Patterns Across Sectors}

In this section, we document three facts about attrition and value-added in Massachusetts. In Section 3.1, we show that charter schools are more likely than traditional public schools to lose both their best and worst teachers. Broadly speaking, attrition patterns in the charter school sector exhibit a U-shape with respect to teacher quality, while attrition in the traditional public sector is either flat or exhibits a downward slope. In Section 3.2 we examine the relation between school value-added and attrition. We find that overall attrition is lower in higher valueadded schools in the traditional public sector, but that there is no comparable gradient among charter schools. In Section 3.3, we show that the relation between attrition and teacher valueadded is similar across low-and high-performing charter schools. This suggests the U-shaped attrition pattern is a general feature of the Massachusetts' charter school model and not a driver of differences between low-and high-value-added charter schools.

\subsection{Charter Schools Differentially Lose their Best and Worst Teachers}

We wish to flexibly estimate the relation between a teacher's rank in the within-school valueadded distribution, time in district, and attrition by sector. To do this, we bin our within-school teacher value-added estimates $\left(\hat{\delta}_{j s}\right)$ into quintiles. ${ }^{12}$ We also split the sample between teachers with 1-3 years time in district and 4-7 years time in district. The logic for this split is that employment protections in Massachusetts are introduced in the traditional public sector after a

\footnotetext{
${ }^{12}$ Quintiles provide a nice trade-off between sample size per cell in the charter school sector (approximately 200) and more fully characterizing the distribution. We have also plotted these relationships with more or fewer bins, and we have also nonparametrically estimated the relevant conditional expectation functions without binning, and the pattern of results shown in this section continue to hold. These results are available upon request.
} 
teacher's 3rd year of in-district employment. In practice, the basic results are robust (if noisier) if we leverage the full support of the time in district variable by estimating the relationship between teacher value-added and attrition separately for each value of time in district. We do not examine teachers with greater than 7 years of time in district for this analysis as there were very few of them in the charter school sector during the time period covered in our data (see Table 3); hence, we are limited in our ability to make meaningful comparisons for teachers at later stages of their career. However, the basic message does not change if we examine teachers with greater than 7 years of tenure as well. See Appendix C.2 for more detail.

Observe that inference in this setting will require us to account for the additional variability induced by the fact that our independent variable (teacher value-added) is itself an estimated quantity. We account for this additional variability by calculating standard errors via a parametric bootstrapping procedure that resamples (and hence clusters) at the teacher level. See Appendix C.1 for more detail on the specifics of the procedure. Note that, in some of our figures, and in particular in some of our appendix figures where we cut the data quite finely, the bootstrap results in $95 \%$ confidence regions that are asymmetric around the point estimate. Intuitively, this can happen when the finite sample distribution of the estimator exhibits multiple peaks, which is the case here since we are placing teachers into bins based on their estimated value-added. Specifically, when we resample, the value added estimates for teachers change, sometimes placing them in a different quintile, which can in turn cause the bootstrap distribution to be bimodal. However, this should not affect inferences made using the boundaries of the confidence interval. So while we have included the point estimates in the figures, we would encourage the reader to interpret the figures visually by comparing how the confidence regions evolve across the value-added distribution.

Figure 1 displays the results for attrition. The dark points are conditional means for the charter school sector within the corresponding value-added quintile as indicated on the $\mathrm{x}$-axis. Whiskers correspond to the $95 \%$ confidence intervals from the bootstrap distribution. The triangles and associated whiskers are analogous estimates for teachers employed at traditional public schools.

Among early career teachers, attrition in the charter school sector exhibits a U-shaped pattern with respect to value-added, while in the traditional public sector, it exhibits a small downward slope. Among mid-career teachers (i.e., after employment protections are introduced in the traditional public schools), we see a similar pattern for math. For ELA teachers, the gap in the upper tail remains, while the gap in the lower tail declines; however, we sound a note of caution here. The charter school estimates, especially in the post-tenure period, have a much smaller sample size and hence are noisier. The broad pattern, across all panels, would seem 


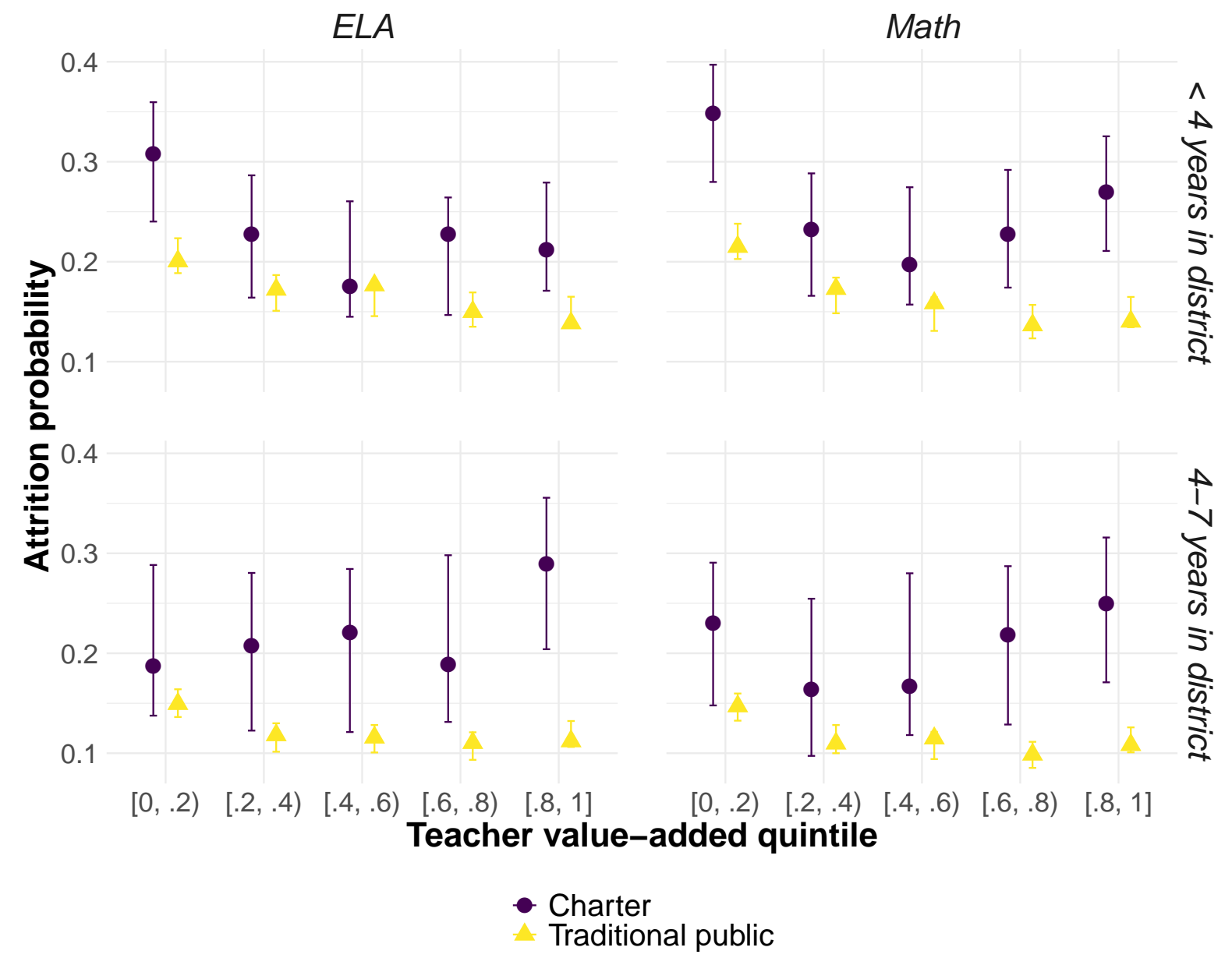

FigURE 1: Attrition and Teacher Value Added

Note: This figure documents how teacher attrition varies with teacher value-added for both math and ELA teachers. "Attrit" takes a value of 1 if the teacher is employed in school $s$ at time $t$ but not at time $t+1$. " $<4$ years in district" refers to teachers who have been employed in their current district less than 4 years. "4-7 years in district" refers to teachers who have been employed in their current district not less than 4 but no more than 7 years. The $\mathrm{x}$-axis plots quintiles of the within sector distribution of teacher value-added. Dots are conditional means for the sample of charter school teachers. Triangles are conditional means for the sample of traditional public school teachers. Vertical bars represent $95 \%$ confidence intervals. Horizontal lines represent the relevant sectoral mean. For the numerical values that underly this figure, see Appendix E. 
to indicate that while attrition is generally higher in charters than in the public sector across all quintiles, the gaps are wider in the tails of the distribution, with perhaps the one exception being the lower tail of the ELA distribution among mid-career teachers.

However, it is possible that these patterns obscure important heterogeneity in attrition with respect to the quality of the school. This is especially important in our setting, where the literature has recovered a wide range of charter school impacts. If the attrition gap among high value-added teachers decreases with school value-added as a result of flattening upper tail attrition in the charter school sector, this would suggest that high quality charter schools are able to better retain their best teachers. Similarly, if charter schools use their increased employment flexibility to remove low performers, we would expect the gap in the lower tail of the teacher value-added distribution to increase with school value-added. Thus we address the relation between attrition and school value-added in the next two sections.

\subsection{Attrition and the School Value-Added Gradient}

As a precursor to examining the two-way interaction between school and teacher value added, we first document how attrition varies with school value-added. We do this flexibly by binning the school value-added distribution into quintiles and splitting the sample of teachers into groups by whether they have completed their 3rd year of time-in-district. The logic behind these splits is similar to that outlined in the preceding section; however, the big picture takeaways are robust to adding more bins, conditioning on the full support of time-in-district, or nonparametrically mapping school quality directly into attrition. Figure 2 plots point estimates and $95 \%$ confidence intervals calculated using the previously described bootstrap procedure.

Attrition in the traditional public sector exhibits a downward gradient with respect to school value-added. This is especially true among early career teachers. There is a 7 percentage point difference in attrition probability for math teachers at the bottom of the school valueadded distribution relative to the top. ${ }^{13}$ Among teachers with enough time-in-district to qualify for tenure, the difference in attrition probabilities at the top and bottom of the distribution is approximately 4 percentage points. These findings broadly replicate the patterns found in the traditional public sector in Florida in Loeb et al. (2012).

There is no discernible pattern between attrition and school value-added in the charter sector. However, we note that the estimates in the charter school sector are based on significantly fewer observation and hence are more noisy. It is possible that with more power, we would pick up a similar gradient as in the traditional public schools. It is also possible that this find-

\footnotetext{
${ }^{13}$ The attrition difference between the top and bottom for ELA teachers is 8 percentage points.
} 


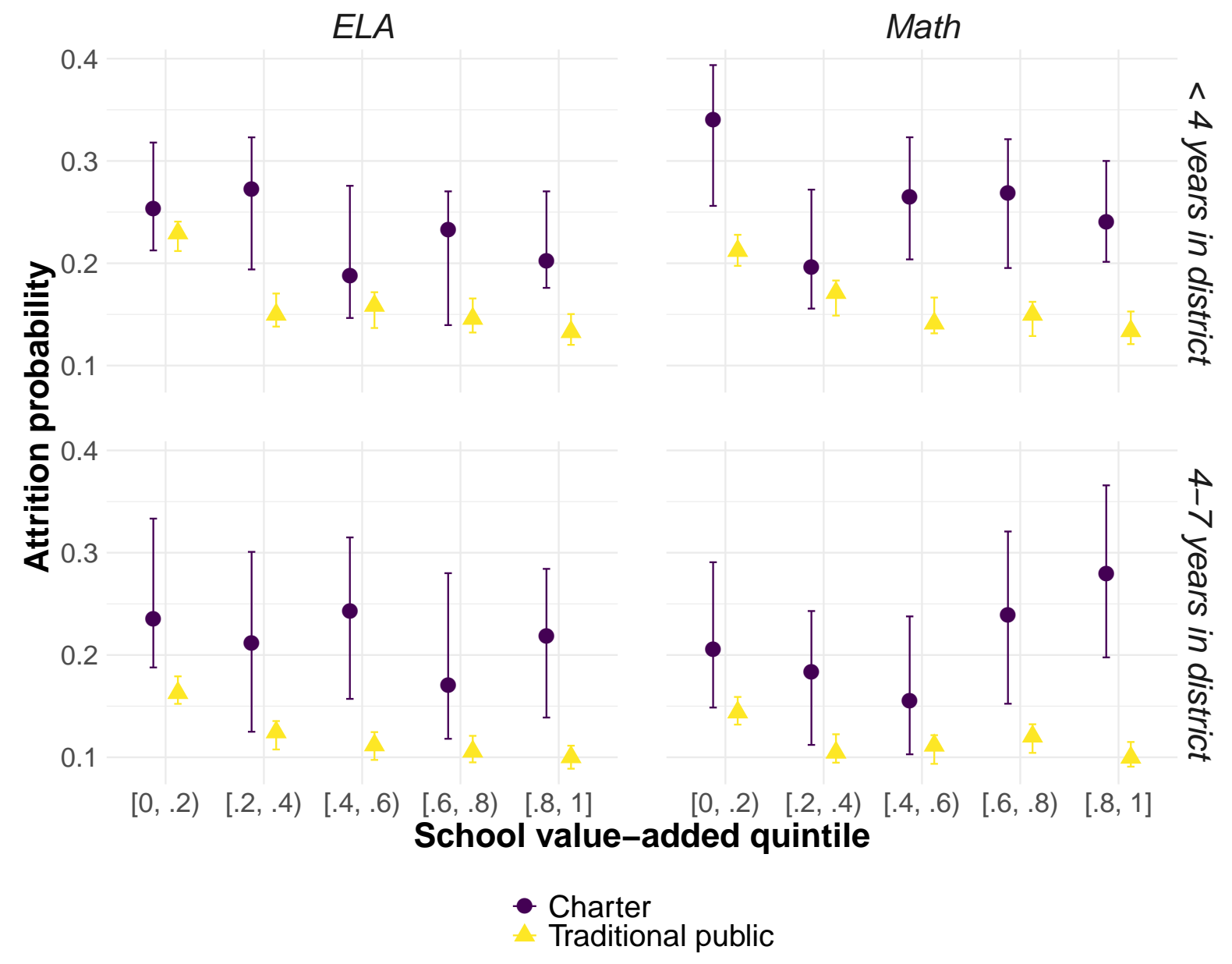

FIGURE 2: School Value-Added and Teacher Attrition by Sector

Note: This figure documents how attrition varies with school value-added in each sector for both math and ELA teachers. "Attrit" takes a value of 1 if the teacher is employed in school $s$ at time $t$ but not at time $t+1$. "<4 years in district" refers to teachers who have been employed in their current district less than 4 years. " $4-7$ years in district" refers to teachers who have been employed in their current district not less than 4 but no more than 7 years. The $\mathrm{x}$-axis represents quintiles of the distribution of school value-added. Dots are conditional means for the sample of charter school teachers. Triangles are conditional means for the sample of traditional public school teachers. Vertical bars represent $95 \%$ confidence intervals. For the numerical values that underly this figure, see Appendix E. 
ing masks more subtle patterns with respect to attrition and school quality. If high-quality charter schools are better at retaining their best, but also removing their worst teachers, these two effects could offset and mask important differences within the quality distribution. We address this possibility in the next section.

\subsection{Attrition by School and Teacher Value-Added}

We conclude this part of the paper by examining the two-way interaction between school and teacher value-added. It is possible that the high value-added charter schools are effective precisely because they are able to leverage their employment flexibility to differentially remove their worst teachers and retain their best. Thus we cut the sample according to whether a school is in the top or bottom 2 quintiles of the school value added distribution. ${ }^{14}$ For visual clarity, we restrict attention to math teachers. The results are similar for ELA teachers. See Appendix C. 5 for more detail. Confidence intervals are calculated via the bootstrap procedure described previously.

Figure 3 presents the results. We first discuss the charter sector. Among teachers with 4-7 years in district in the charter sector, we see the familiar U-shaped pattern with respect to teacher value-added and attrition in both high and low-performing schools. We also see this pattern among charter teachers with less than 4 years in district in low-performing schools. While the U-shape is not apparent in high-performing charter schools among teachers with less than 4 years in district, there also does not appear to be any striking evidence that charter schools are differentially removing their worst teachers or retaining their best. Instead, it would seem that the best, most experienced teachers leave at higher rates regardless of underlying charter school performance.

For traditional public schools, there is very little difference in attrition risk for mid-career teachers between high-and low-performing schools along the teacher value-added distribution. However, there is a stark difference in attrition among early career teachers between low-and high-performing traditional public schools. There we observe that the worst teachers within the low-performing schools are nearly 7 percentage points more likely to leave than the worst teachers at the high-performing schools. This is hard to reconcile with the idea that effective traditional public schools are better at recognizing and removing their worst teachers in the pre-tenure period.

\footnotetext{
${ }^{14} \mathrm{We}$ choose to use the top 2 quintiles rather than just the top quintile for power. If we restricted ourselves to just the top and bottom quintile, then results for the charter sector would effectively be based on 14 schools per grouping, further subdivided by the number of teachers falling into value-added quintiles within that group. That said, we get qualitatively similar conclusions if we choose this more restrictive definition of high-and low-quality. See Appendix C. 4 for more details.
} 


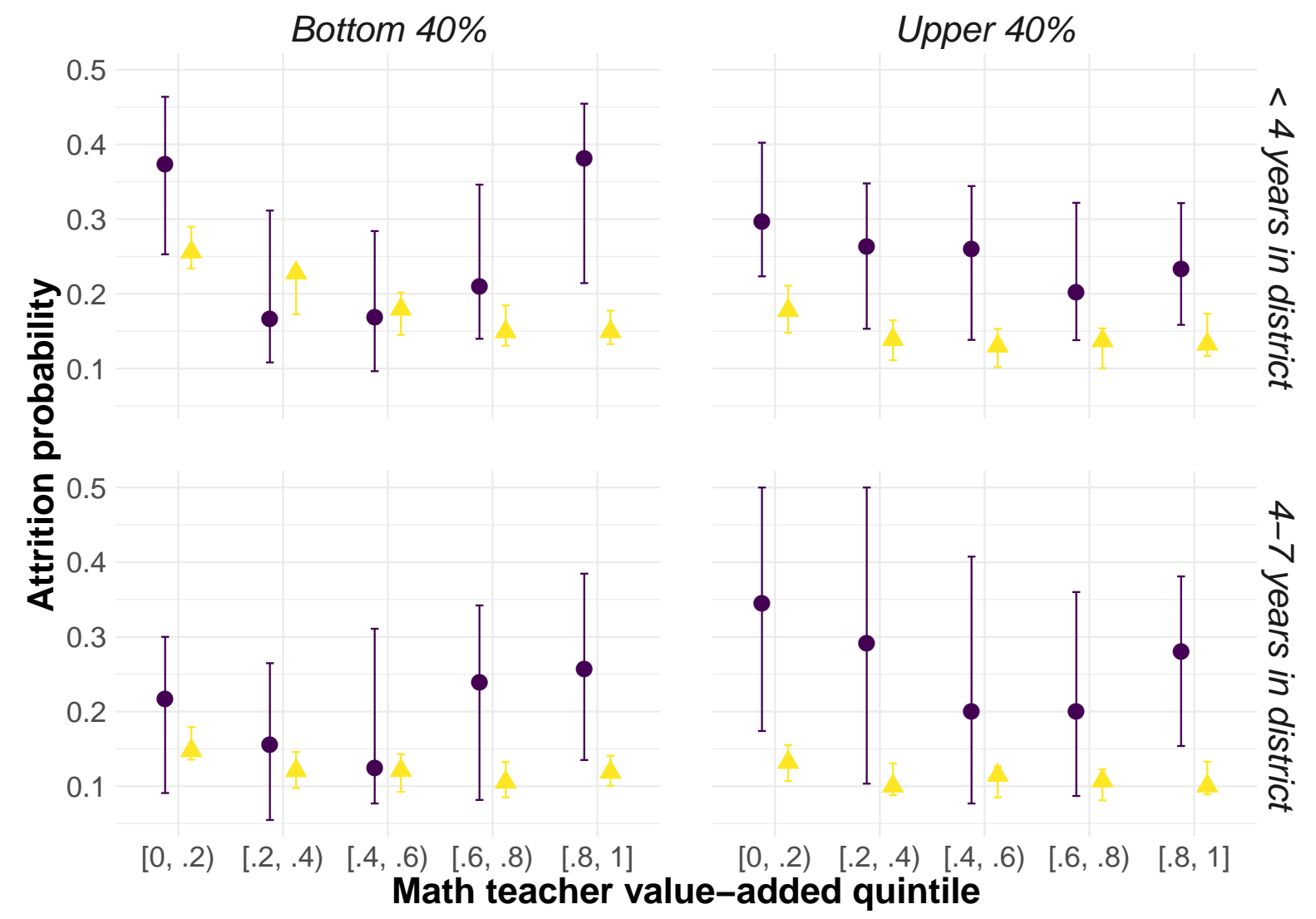

- Charter

Traditional public

\section{Figure 3: School Value-Added, Math Teacher Value Added, and Attrition by Sector}

Note: This figure documents how the differential relationship between attrition and teacher quality across sectors varies with the quality of schools for math teachers. "Attrit" takes a value of 1 if the teacher is employed in school $s$ at time $t$ but not at time $t+1$. " $<4$ years in district" refers to teachers who have been employed in their current district less than 4 years. "4-7 years in district" refers to teachers who have been employed in their current district not less than 4 but no more than 7 years. "Bottom $40 \%$ of Schools" refers to schools in the bottom quintile of the within sector distribution of estimated school value-added. "Top 40\% of Schools" refers to schools in the top quintile of the within sector distribution of estimated school value-added. The x-axis plots quintiles of the within sector distribution of teacher value-added. Dots are conditional means for the sample of charter school teachers. Triangles are conditional means for the sample of traditional public school teachers. Vertical bars represent $95 \%$ confidence intervals. 
In our view, the results in this section cut heavily against the idea that the exercise of the flexible employment practices afforded charter schools is an important mediator of success within that sector. The fact that attrition patterns are so similar across the school value-added distributions suggests that U-shaped attrition is a feature of charter schools in Massachusetts generally rather than a driver of differences between them. And while there are important differences in attrition between high and low performing traditional public schools across the distribution of school quality, the empirical patterns we find are opposite of what we would expect if regulatory barriers were an important driver of quality differences there. Taken together, these results suggest that other environmental factors are the first-order drivers of attrition in both sectors.

\section{Mobility and Teacher Licensure}

We now examine the pathways that charter school teachers take through the labor force. In Section 4.1, we show that low value-added teachers who leave the charter sector are relatively more likely to exit the educator labor force, while high value-added teachers are relatively more likely to move on to other schools. This is consistent with charter schools serving as an entry point into the educator labor force for high-quality teachers who would otherwise be unqualified for jobs in traditional public schools. In Section 4.2, we document that the timing of licensure is highly predictive of teacher mobility across sectors, which suggests that licensure may play an important role in explaining this pattern of facts.

\subsection{Destinations of Attriting Teachers}

We now explore the destinations of teachers who attrit. Recall that we say a teacher has attrited if they are employed in school $s$ at time $t$ but not at time $t+1$. We define teacher movement if they have attrited at time $t$, but are employed at any other public school in Massachusetts (charter or traditional) at time $t+1$. We define a teacher exit if they attrit at time $t$ but do not appear in any school in Massachusetts at time $t+1$. Figure 4 plots fully nonparametric estimates

of the conditional expectation function mapping years in district into teacher movement and exits.

Figure 4 reveals that high attrition in the charter school sector relative to traditional public schools is a phenomenon almost entirely driven by teachers exiting the educator labor force. At any given level of time in district, at least $67 \%$ of the gap in attrition between charter schools and traditional public schools is due to higher exits in the charter sector. However, the 


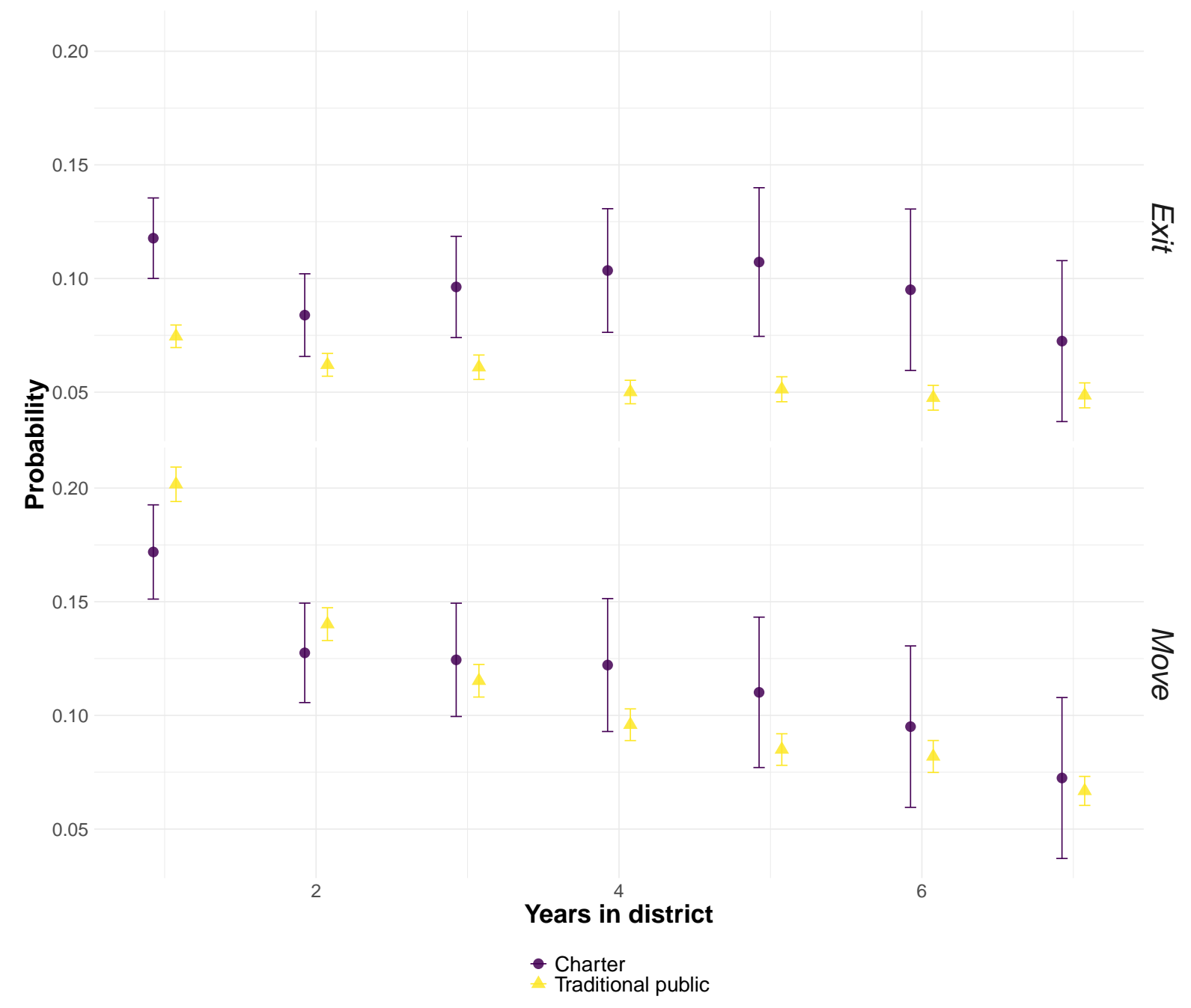

Figure 4: Decomposing Teacher Attrition

Note: This figure documents how different types of teacher attrition vary with time in district. "Move" takes a value of 1 if a teacher attrits at time $t$ but is employed as a teacher in some other school in our data as of time $t+1$. "Exit" takes a value of 1 if the teacher attrits time $t$ but does not work as a teacher in any public school in Massachusetts as of time $t+1$. "Years in district" is defined as the number of years since date of hire in the current district. Dots are conditional means for the sample of traditional public school teachers. Triangles are conditional means for the sample of charter school teachers. Vertical bars represent $95 \%$ confidence intervals. For the numerical values that underly this figure, see Appendix E. 
difference is most stark in the first year of employment, where $90 \%$ of the difference in attrition is the result of more exits in charter schools.

Figure 5 shows how moves and exits vary across the teacher value-added distribution. As in Section 3.1, we split the sample by whether a teacher has enough time in district to qualify for employment protections and plot conditional means at quintiles of the within-school valueadded distribution. We focus on math teachers here for visual clarity, but similar patterns hold for ELA teachers (see Appendix C.6).

Relative to traditional public schools, charter school attrition in the lower tail of the valueadded distribution is disproportionately comprised of exits. This is true for teachers at levels of within district experience that would or would not qualify them for employment protections. Among teachers in the charter sector with less than 4 years in district in the lowest quintile of the value-added distribution, there is an 9.9 percentage point higher probability that they exit relative to traditional public school teachers with similar value-added. The same comparison for moves reveals a 4 percentage point difference. Among teachers with enough time in district to qualify for employment protections, the difference in exit rates is 7.3 percentage points; the difference in movement rates less than 0.1 percentage points.

In the upper tail of the value added distribution, the pattern varies by experience. Among teachers with enough time in district to qualify for employment protections, the difference in exit rates is 4.8 percentage points, while for moves it is 9.4 percentage points. Among teachers with less than 4 years time-in-district, the differences are 7.6 percentage points for exits and 5.4 percentage points for movement rates. Thus, attrition among high value-added midcareer teachers disproportionately consists of movement to other public education employment opportunities, while among early-career teachers it is more equally split between exits and movement.

Taken together, the evidence in this section is consistent with the idea that the lack of employment protections in the charter sector allows these schools to serve as a pathway into the educator labor force for high-quality teachers who are otherwise unqualified for jobs in the traditional public sector. Charter school teachers in the lower tail of the value-added distribution are more likely to exit the labor force relative to traditional public schools. In the upper tail, they are relatively more likely to move on to other public school teaching positions. However, we caveat this with the fact that this is largely driven by teachers with enough time in district to qualify them for employment protections at traditional public schools; the comparison among less experienced teachers weakly favors exits. 


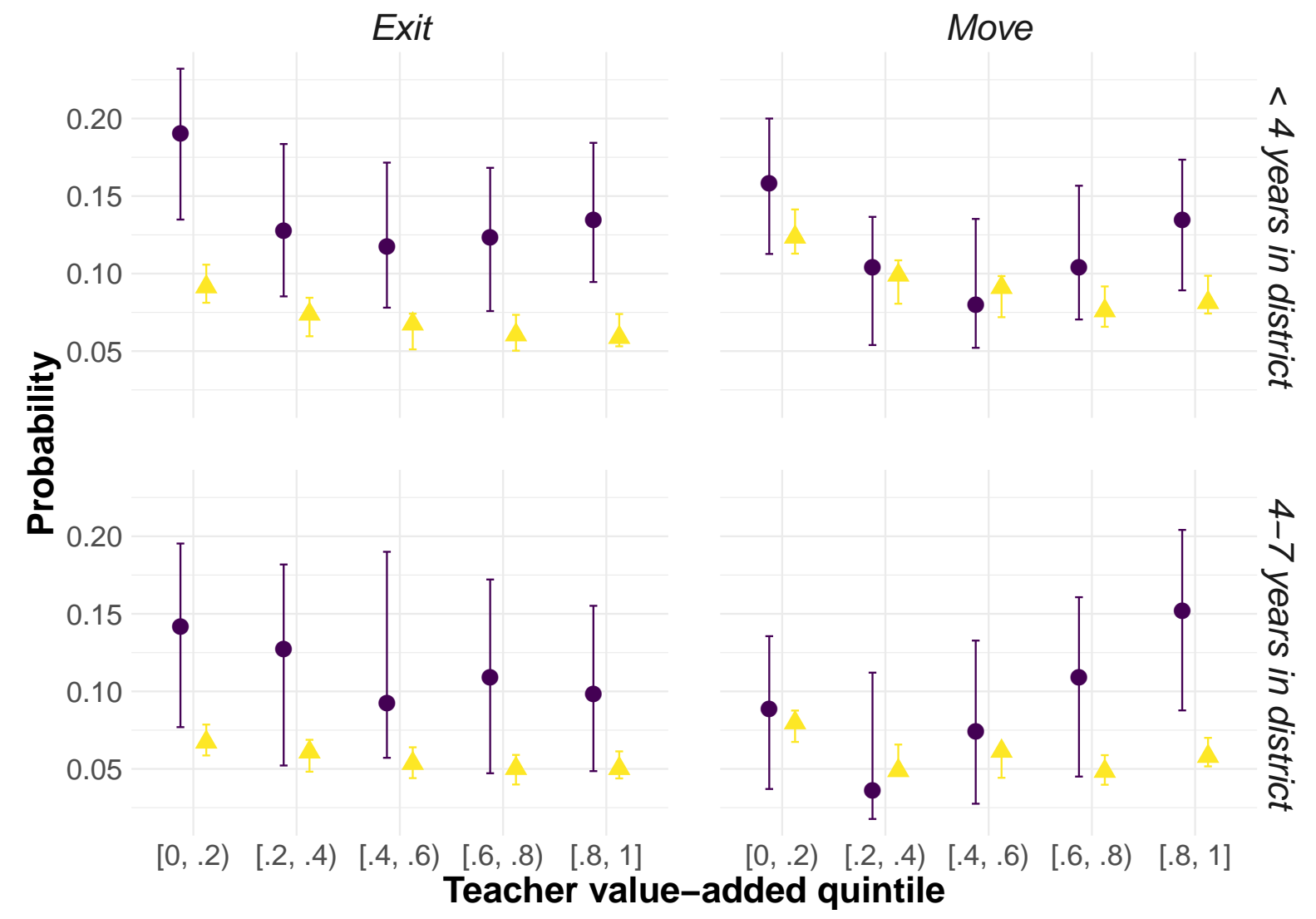

- Charter

- Traditional public

FIGURE 5: Decomposing Math Teacher Attrition by Value-Added

Note: This figure decomposes the differential relationship between attrition and math teacher value-added across sectors into different attrition types. "Move" takes a value of 1 if a teacher attrits at time $t$ but is employed as a teacher in some other school in our data as of time $t+1$. "Exit" takes a value of 1 if the teacher attrits time $t$ but does not work as a teacher in any public school in Massachusetts as of time $t+1$. "< 4 Years-in-District" refers to teachers who have been employed in their current district less than 4 years. "4-7 Years-in-District" refers to teachers who have been employed in their current district not less than 4 but no more than 7 years. The $\mathrm{x}$-axis represents quintiles of the within sector distribution of teacher value-added. Dots are conditional means for the sample of charter school teachers. Triangles are conditional means for the sample of traditional public school teachers. Vertical bars represent $95 \%$ confidence intervals. For the numerical values that underly this figure, see Appendix E. 


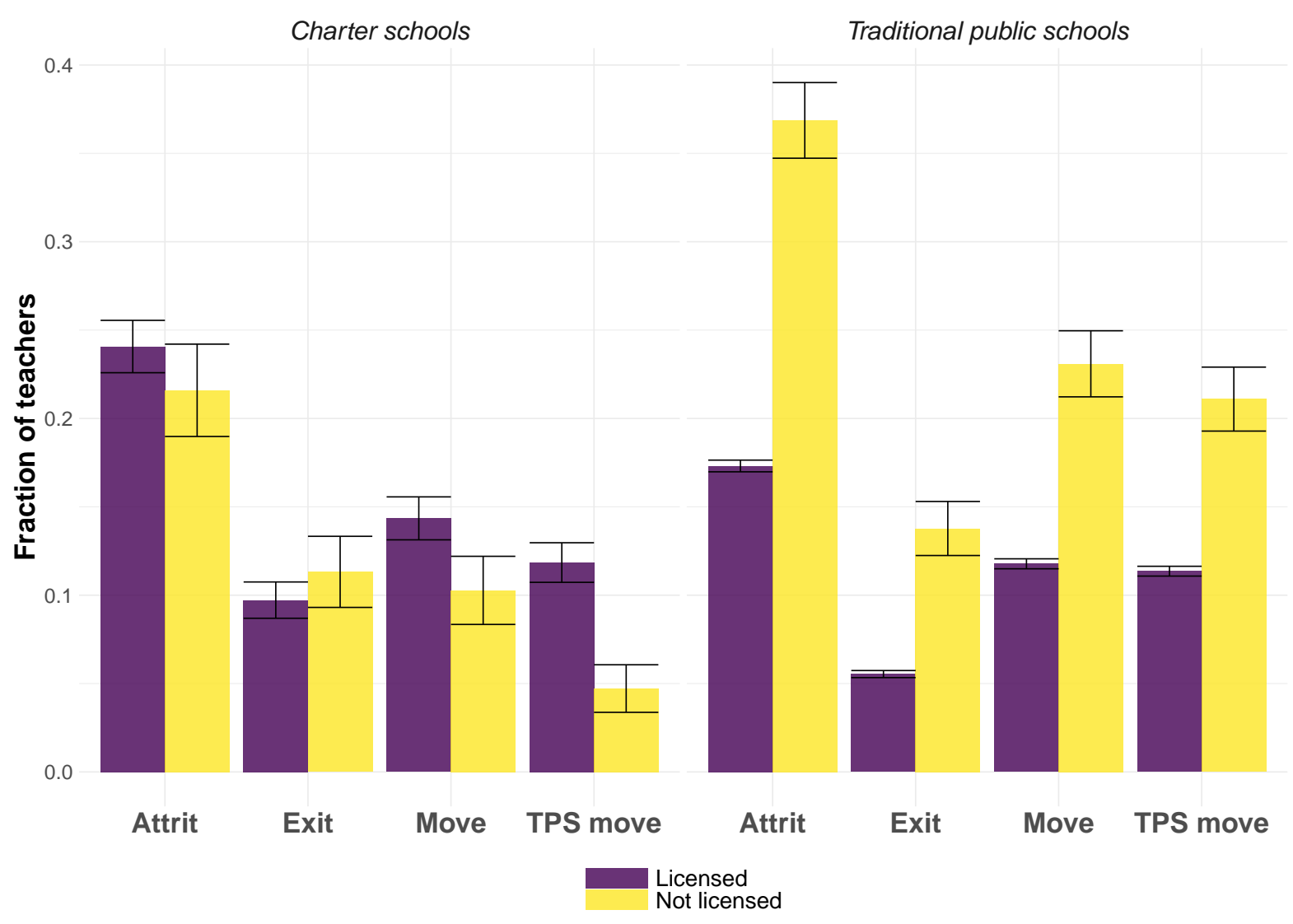

Figure 6: Attrition Patterns by Licensure Status in Charter and Traditional Public Schools

Note: This figure plots attrition patterns for licensed and unlicensed teachers in the charter and traditional public school sectors. "Attrit" takes a value of 1 if a teacher is employed in school $s$ at time $t$ but not at time $t+1$. "Move" takes a value of 1 if a teacher attrites at time $t$ but is employed as a teacher in some other school in our data as of time $t+1$. "Exit" takes a value of 1 if the teacher attrits time $t$ but does not work as a teacher in any public school in Massachusetts as of time $t+1$. The bars denote means for licensed teachers (dark shading) and unlicensed teachers (light shading). The whiskers denote 95\% confidence intervals around the mean. The left panel describes attrition in charter schools. The right panel describes attrition in traditional public schools.

\subsection{Unlicensed Teacher Attrition}

We now turn to the hiring side. Recall from Table 2 that in an average year over this period, $20-22 \%$ of the math/ELA teachers in our sample who worked in charter schools did not have a license, compared to just $2 \%$ of teachers in traditional public schools. Thus, it would seem that charter schools hire from a different pool of labor than their traditional public school peers. We will now explore how these unlicensed teachers move through the labor force in each sector. Figure 6 plots means and 95\% confidence intervals for different types of attrition among licensed and unlicensed teachers in the charter and traditional public school sector for our main estimation sample of teachers.

There are several patterns of note in Figure 6. First, observe that attrition rates are extremely high among unlicensed teachers in traditional public schools. This is likely due to the 
fact that traditional public school teachers are eligible to be hired on a 1-year waiver without a license; however, their continued employment is contingent upon successfully obtaining a license prior to the following academic year. Thus, teachers who remain unlicensed are barred from returning to work at the same school. There is no similar disparity in attrition between licensed and unlicensed teachers in charter schools. Second, observe that licensed teachers in the charter school sector move to traditional public schools at very high rates - even higher than licensed teachers in traditional public schools.

One possible explanation for this pattern is that teachers are entering the charter sector, where both pay and barriers to entry are low, in order to learn their taste for the teaching profession. If this is true, we expect that those who enjoy teaching and decide to pursue it as a career will subsequently obtain a license and move to the traditional public sector, where pay and benefits are typically higher.

To examine this possibility, we look at all educators in Massachusetts who have ever worked unlicensed as a teacher in a charter school and who subsequently obtain a license. ${ }^{15}$ With this sample, we estimate models of the following form:

$$
d_{i t}=\delta_{i}+\delta_{t}+\sum_{\mathbb{T}} \beta_{\tau} \ell_{i \tau}+u_{i t}
$$

Where $d_{i t}$ is an indicator that takes a value of 1 when teacher $i$ is employed in a public school at time $t ; \delta_{i}$ and $\delta_{t}$ are teacher and year fixed effects, respectively; $\tau=t_{i}-t$ indexes time relative to the year that teacher $i$ obtained their license $\left(t_{i}\right) ; \mathbb{T}$ denotes the set of event times omitting the year immediately prior to licensure $(\tau=-1)$ and the first event year $(\tau=-8)$; and $\ell_{i \tau}$ is an indicator that takes a value of $1 \tau$ years before/after teacher $i$ obtains their license. Thus, the coefficient $\beta_{\tau}$ measures the change in probability that a teacher works in a public school $\tau$ years before/after they obtain their license relative to themself in event year $\tau=-1$ and also relative to the same pre-post comparison for the average teacher who has not yet obtained their license. Figure 7 displays the results.

Note that we do not wish to suggest that these event study coefficients are causal. ${ }^{16}$ It is almost certainly the case that the timing of licensure coincides with a decision by the teacher to look for employment in the traditional public sector. Despite not being causal, we believe the event study coefficients are still interesting for two reasons. First, they reveal that the decision

\footnotetext{
${ }^{15}$ If we also require that the teacher appears in our value-added sample, we are left with a small number of teacher observations (244). Hence we prefer to use the entire sample of teachers for this exercise.

${ }^{16}$ In other words, if we randomly gave licenses to teachers in the charter sector, we would not expect their movement propensities to match those we recover in the event study.
} 


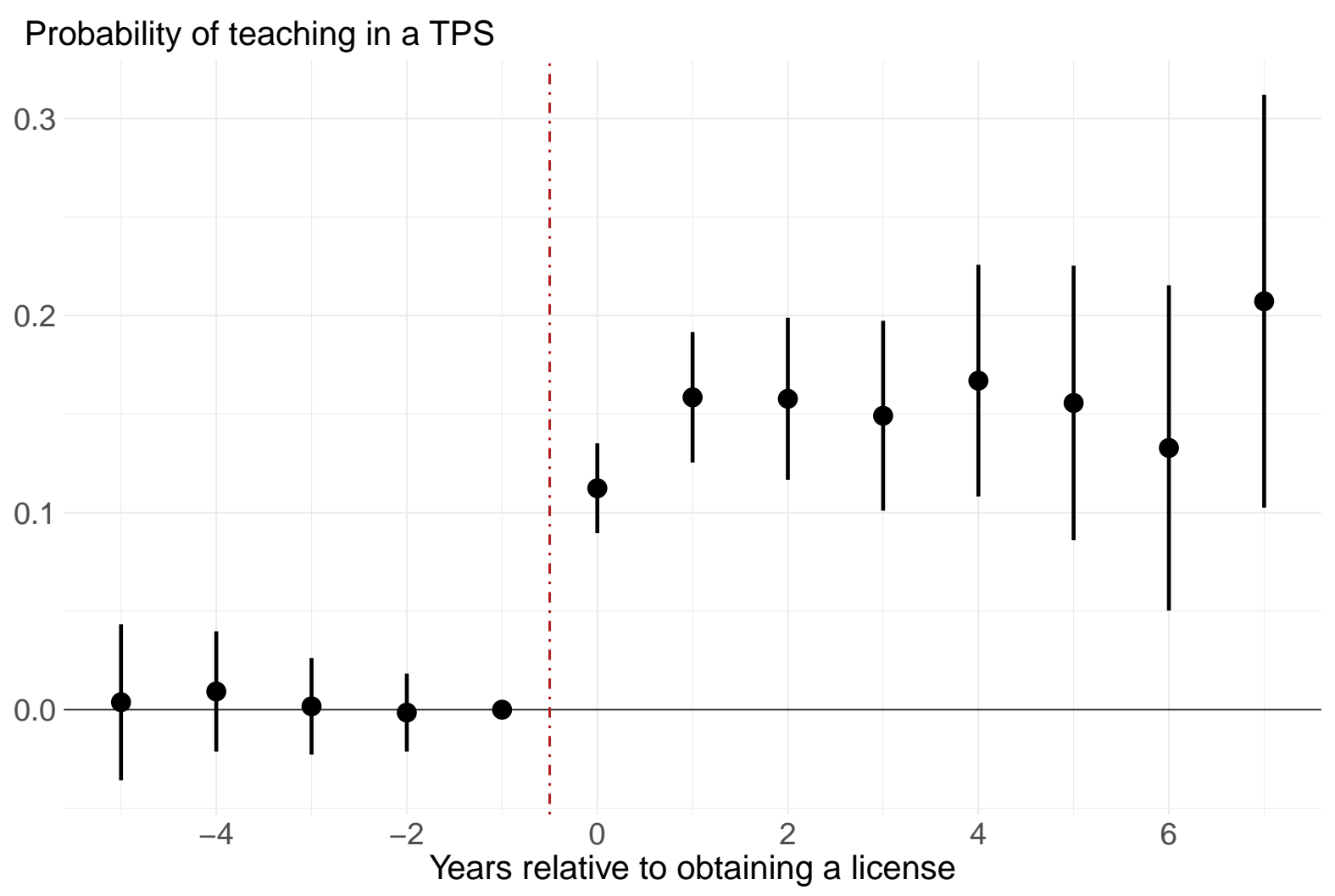

FIGURE 7: Charter Teachers Obtain Licenses Immediately Prior to Switching Sectors

Note: This figure plots event study coefficients for the model $d_{i t}=\delta_{i}+\delta_{t}+\sum_{\mathbb{T}} \beta_{\tau} \ell_{i \tau}+u_{i t}$ as estimated on the sample of teachers who ever work unlicensed in a charter school. Here $d_{i t}$ is an indicator that takes a value of 1 when teacher $i$ is employed in a public school at time $t ; \delta_{i}$ and $\delta_{t}$ are teacher and year fixed effects, respectively; $\tau=t_{i}-t$ indexes time relative to the year $\left(t_{i}\right)$ that teacher $i$ obtained their license; $\mathbb{T}$ denotes the set of event times omitting the year immediately prior to licensure $(\tau=-1)$ and the first event year $(\tau=-8)$; and $\ell_{i \tau}$ is an indicator that takes a value of $1 \tau$ years before/after teacher $i$ obtains their license. The plotted coefficients reveal that the decision by a teacher to obtain a license is highly predictive of a move from the charter school to a traditional public school, and that such changes are largely permanent. For the numerical values that underly this figure, see Appendix E. 
to obtain a license by a teacher in the charter sector is highly predictive of an immediate move to the traditional public sector. A charter teacher's probability of switching to a traditional public school increases by 11.2 percentage points in the year after obtaining a license. This is what we would expect if teachers use charter school employment as a method to learn about their taste for teaching without committing to the fixed cost of licensure. Second, the dynamics of the event study reveal that these switches are largely permanent. In years 2-8 after obtaining a license, the increase in probability that the unlicensed teacher works in a public school ranges from 13 to 20 percentage points. Thus, once teachers commit to the fixed cost of licensure, they rarely return to the charter sector, which is consistent with the fact that total compensation in the form of higher pay and increased job security are much larger in traditional public schools than they are in charter schools. In the next section, we show that the empirical pattern in Figure 7, along with the attrition patterns described earlier in the paper, are consistent with a simple model of teacher labor markets that incorporates frictions from licensure requirements in the traditional public sector.

\section{Teacher Attrition and Regulatory Arbitrage}

To this point, we have established the following facts:

1. Charter schools differentially lose their highest and lowest performing teachers.

2. Attrition among low value-added charter school teachers is disproportionately comprised of teachers exiting the public education labor pool, while attrition among high valueadded charter school teachers is disproportionately comprised of movement to other public education employment opportunities.

3. Charter school teachers are more likely to be unlicensed; however, once they obtain a license, the probability they subsequently take a job in a traditional public school immediately and persistently increases.

In this section we show that a simple model of teacher learning in the presence of licensure requirements offers one plausible way to rationalize these facts.

Assume there is a unit mass of educators with period utility given by:

$$
u=w+\theta-\chi
$$


Where $w$ is the wage; $\chi$ is the fixed cost of time associated with work; and $\theta$ is a uniformly distributed taste for teaching with support on the interval $[0,1]$. We assume that teachers with high $\theta$ exert more effort at any given wage and thus generate higher value-added. Thus we take $\theta$ as synonymous with teacher quality. Importantly, we assume that taste for teaching $(\theta)$ is initially unknown to the educator. We also assume that educators are small with respect to the overall labor market and hence do not consider how their labor supply choices affect wages in equilibrium.

The local public school $(p)$ has perfectly inelastic demand for teachers and pays a wage $\left(w_{p}\right)$ which is determined exogenously via a bargaining process between the union and the school board. We also assume that state-level regulations require the public school to hire only teachers with licenses.

Each period, the local charter school $(c)$ hires a mass of educators $(\mathbb{S})$ who may or may not be licensed, pays them a wage $\left(w_{c}\right)$, and receives period utility:

$$
\pi=F(\Theta)-w_{c} \mathbb{S}
$$

Where $F$ is a technology that transforms total teacher quality $(\Theta)$ into charter school utility as measured in dollars. ${ }^{17}$ Note that $\mathbb{S}$ and $\Theta$ are determined by the labor supply choices of teachers, which in turn depend on the wage $\left(w_{c}\right)$ chosen by the charter school. Observe that by our choice of objective function we have implicitly assumed that charter schools do not pay efficiency wages and hence cannot discriminate in their hiring based on teacher quality $(\theta)$. We believe this choice is reasonable for the purposes of explaining the empirical patterns in this paper, since there is evidence that subjective teacher reviews are only weakly predictive of value-added (Jacob \& Lefgren, 2008; Bacher-Hicks et al., 2019). Also, to simplify the math in a way that emphasizes the role of teacher learning and option value, we assume that charter schools cannot condition wages on licensure status or employment history, and we will not allow them to vary the wages they offer over time. ${ }^{18}$ Last, we will restrict attention to a twoperiod model, and thus assume that educators and the local charter school discount at rates $\rho$ and $\delta$ respectively.

At the start of each period, teachers may pay an idiosyncratic ${ }^{19}$ and uniformly distributed

\footnotetext{
${ }^{17}$ Note that this formulation nests as special cases both a profit-maximizing charter school and an altruistic charter school that seeks to maximize the benefit to students.

${ }^{18}$ However, we believe the basic results would hold for these more complicated cases.

${ }^{19}$ This would be the case if, for example, teachers have differing financial resources or heterogenous tastes for leisure time or classroom learning.
} 
cost $k$ with support on the interval $[0,1]$ to complete a teacher preparation program, learn their type $(\theta)$, and obtain a license. Once educators have made a decision regarding licensure, they may choose to supply their unit of labor to the school of their choice at the prevailing wages, or they may take their outside option which we normalize to be zero (i.e., $u_{0}=0$ ). After the first period, teachers who chose to work in the charter school learn their type $(\theta)$ via their on-the-job experience and reoptimize.

Consider the decision by teachers to obtain a license in the initial period. Let $v_{\ell}=v_{\ell}(\theta, k)$ be the discounted value of utility over both periods for a teacher of type $(\theta, k)$ if they obtain a license at time 1 , and let $v_{0}$ be the discounted value of utility if they do not. Let $\ell$ be an indicator that takes a value of 1 if a teacher obtains a license. Then the licensure decision at time 1 is given by:

$$
\ell= \begin{cases}0 & k>\mathbb{E}\left(v_{\ell}-v_{0}\right) \\ 1 & k<\mathbb{E}\left(v_{\ell}-v_{0}\right)\end{cases}
$$

In Appendix D, we show that the period one behavior of teachers with a low cost of licensure $\left(k<w_{p}-w_{c}\right)$ reduces to:

$$
\ell_{k<w_{p}-w_{c}}= \begin{cases}0 & k+\frac{\rho}{2} k^{2}>w_{p}-w_{c}-P\left(\theta<\chi-w_{p}\right) \mathbb{E}\left(u_{p} \mid \theta<\chi-w_{p}\right) \\ 1 & k+\frac{\rho}{2} k^{2}<w_{p}-w_{c}-P\left(\theta<\chi-w_{p}\right) \mathbb{E}\left(u_{p} \mid \theta<\chi-w_{p}\right)\end{cases}
$$

Where $u_{c}=u\left(w_{c}\right)$ and $u_{p}=u\left(w_{p}\right)$. From these inequalities we can define a threshold $k^{\dagger}\left(w_{c}\right)$ as the solution to the implied polynomial occurring at the indifference point. To better understand how this threshold is determined, note that $\frac{1}{2} k^{2}$ is the option value that accrues to an individual when they choose to learn their type in the charter sector before committing to the fixed cost of licensure. Thus, we can read the left-hand side of this inequality as representing the total economic cost of obtaining a license: the explicit cost $(k)$ plus the properly discounted forgone option value. Next note that $P\left(\theta<\chi-w_{p}\right) \mathbb{E}\left(u_{p} \mid \theta<\chi-w_{p}\right)$ is the loss an individual avoids because they are allowed to drop out of the labor force after buying a license and discovering that their taste for teaching is low. Thus, the right hand side of this inequality is the total benefit to buying a license: the explicit increase in wages unlocked by purchasing a license, plus the information value of learning $\theta$ for teachers who are eligible to work in a traditional public school.

In the appendix, we also show that the behavior of teachers with a high cost of licensure $\left(k>w_{p}-w_{c}\right)$ reduces to: 


$$
\ell_{k>w_{p}-w_{c}}= \begin{cases}0 & k>k^{*}\left(w_{c}\right) \\ 1 & k<k^{*}\left(w_{c}\right)\end{cases}
$$

Where the threshold is given by $k^{*}\left(w_{c}\right)=(1+\rho)\left(w_{p}-w_{c}\right)-(1+\rho) P\left(\theta<\chi-w_{p}\right) \mathbb{E}\left(u_{p} \mid \theta<\right.$ $\left.\chi-w_{p}\right)+\rho P\left(\theta<\chi-w_{c}\right) \mathbb{E}\left(u_{c} \mid \theta<\chi-w_{c}\right)$. To better understand how this threshold is determined, note that $P\left(\theta<\chi-w_{c}\right) \mathbb{E}\left(u_{c} \mid \theta<\chi-w_{c}\right)$ is the value of the loss a teacher may avoid in the second period by learning their type on the job via working in a charter. Thus, the right hand side of the inequality is the total benefit to licensure: the discounted value of the wage differential over both periods plus the properly discounted difference in information value that results from learning $\theta$ through different channels. Educators will buy licenses when the cost $k$ exceeds this expected benefit.

Now that we have determined teacher behavior with respect to licensure in the first period, it is simple to characterize teacher behavior over both periods as a function of $\theta$ and $k$. Figure 8 plots the reaction function. Each polygon in the figure cuts $(\theta, k)$ space into regions of different dynamic behavior; within each polygon, we describe in words the relevant behavior of those teachers at times $t=1$ and $t=2$. Note that "TPS" stands for traditional public school; "LF" stands for labor force.

Observe that the model generates three potential types of nontrivial educator behavior. Educators with the highest licensure costs $\left(k>k^{*}\right)$ are potential "career" charter teachers; they work in the charter school at time 1, learn their type and, if they are high enough quality $\left(\theta>\chi-w_{c}\right)$, will continue to work in the charter school in period 2. The low-quality charter teachers in this group will leave the labor force in the second period.

Educators with moderately high licensure costs $\left(k^{*}>k>w_{p}-w_{c}\right)$ and those with extremely low licensure costs $\left(k<k^{\dagger}\right)$ are potential "career" public school teachers. They will buy a license in the first period, and those who learn they are high quality $\left(\theta>\chi-w_{p}\right)$ will work in the traditional public school for both periods. Those who are low quality will exit the labor force. Note that the educators with moderately high licensure costs buy the license in the first period because they can only hope to recoup the expense over two periods; hence, the option value gained by working in a charter is useless to them. Those with extremely low licensure costs choose this route because, in expectation, the additional wages gained by working in the public sector in the first period exceeds the explicit cost of licensure and the net option value of working in a charter.

Finally, educators with a moderately low cost of licensure $\left(k^{\dagger}<k<w_{p}-w_{c}\right)$ will work in the charter sector in period 1 , learn their type, and those that are high quality $\left(\theta>\chi-w_{p}-k\right)$ will buy a license and switch to the public sector in period 2 . The low-quality teachers in this 


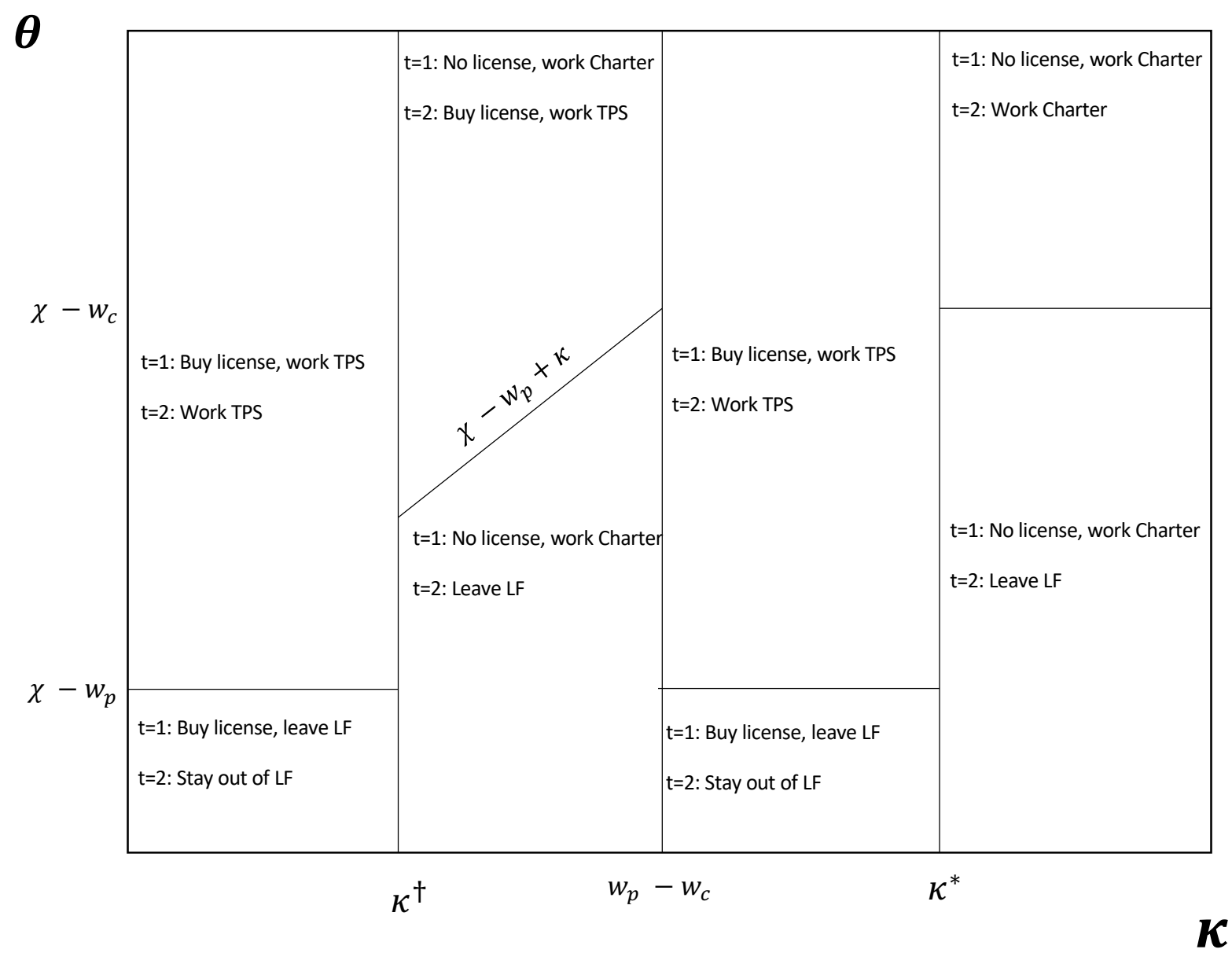

FIGURE 8: Educator Reaction Function

Note: This figure completely characterizes educator behavior as a function of their cost of licensure $(k)$ and their unobserved taste for teaching $(\theta)$. Each polygon in the figure cuts $(\theta, k)$ space into regions of different dynamic behavior; within each polygon, we describe the relevant behavior of those teachers at times $t=1$ and $t=2$. TPS stands for traditional public school. LF stands for labor force. 
region of $k$-space will work in the charter school in period 1 then leave the labor force in period 2. These are the teachers that potentially drive the differential attrition documented earlier in the paper.

In the appendix, we show that there exist portions of the parameter space $\left(w_{p}, \chi, \rho, \delta, F\right)$ such that it is optimal for charter schools to choose a wage that will sustain all three types of educator behavior in equilibrium. Necessary conditions for these equilibria to exist, as well as richer models that consider infinitely many periods and general equilibrium via charter entry/exit or cross district competition, are left for future work.

The important feature of the model for our purpose is that it generates patterns which are consistent with the empirical facts in our data. High-quality and low-quality charter school teachers are differentially likely to attrit from the charter sector. Those with high value-added obtain licenses and move to traditional public schools. Those with low value-added leave the labor force entirely. We note that there is a simpler version of this model that could also rationalize the $\mathrm{u}$-shaped pattern between attrition and value added. Suppose all teachers have a strong preference to work in traditional public schools. Thus they obtain licenses immediately and search in the traditional public school labor market, but some wind up rationed out of the traditional public school work force due to insufficient demand. The teacher may then take a job in a charter school temporarily and continue to search. If the teacher also learns something about their taste for teaching on the job in the charter sector, this could also generate a u-shaped pattern between attrition and value added; however, this simpler version of the model cannot also explain the attrition patterns with respect to licensure documented in figure 7 . So while it is likely that there are other forces at work when it comes to charter teacher attrition, we have chosen to focus on this richer model since it better fits the patterns in our data while also highlighting a novel channel through which charter schools may affect the local public school labor force.

Interestingly, the model implies that charter schools increase the quality of the average teacher employed in traditional public schools. To see this, observe that if there were no charter school in this economy, then educators would buy a license only if $k<(1+\rho) P(\theta>\chi-$ $\left.w_{p}\right) \mathbb{E}\left(u_{p} \mid \theta>\chi-w_{p}\right)$. Subsequently, those who observe $\theta>\chi-w_{p}$ work in the traditional public school for both periods; the rest leave the labor force. Thus, the average quality of a public school teacher in both periods is $\frac{1+\chi-w_{p}}{2}$.

Now consider the impact of adding a charter school. First, observe that average teacher quality in the first period does not change. While the total quantity of teacher labor goes down as a result of some teachers preferring to learn their type on the job in the charter sector rather than buying the license immediately, average quality among teachers who buy the license at 
time 1 is still given by $\frac{1+\chi-w_{p}}{2}$ (see Figure 8 ). However, in the second period, teachers who switch sectors will be positively selected along the quality dimension. From Figure 8, observe that only those teachers with $\theta>\chi-w_{p}+k>\chi-w_{p}$ will switch to the public sector; hence, the average quality of the switching teachers must be higher than that of the public school incumbents, which will in turn raise average quality overall.

\section{Conclusion}

Employment restrictions embedded in collective bargaining agreements, administrative policies, and legislation may inhibit public school effectiveness by limiting their ability to retain effective teachers and remove ineffective teachers (Goldhaber \& Hansen, 2010; Staiger \& Rockoff, 2010; Cowen \& Winters, 2013). We assess whether charter schools are able to take advantage of their freedom from such restrictions by comparing teacher attrition patterns within Massachusetts charter and traditional public schools. We confirm that charter schools experience substantially greater teacher attrition than do traditional public schools. Relative to traditional public schools, charters are more likely to lose both their most and least effective teachers. Finally, we show that this pattern of empirical results could be explained with a model of regulatory arbitrage which predicts that charter schools have a positive impact on the quality of the public school teacher workforce.

Though attrition patterns differ across sectors, we find little empirical evidence to support the claim that employment flexibility contributes meaningfully to charter school effectiveness. The U-shaped relationship between teacher quality and attrition is a common feature of charter schools that is not significantly related to charter school impacts.

Our theoretical results also contribute to the understanding of the impact that charter schools have on the quality of traditional public schools. The evidence on the overall effects of charter school expansion on the quality of nearby traditional public schools is mixed, with the majority of prior studies finding either null or small positive effects (Cordes, 2018; Imberman, 2011b; Bettinger, 2005; Hoxby, 2003; Booker et al., 2008; Bifulco \& Ladd, 2006; Winters, 2012). Prior authors suggest that charter schools could impact public school performance through a combination of altering their available resources or by instilling competition for student enrollment. We add to this literature by describing the potential for charter schools to impact teacher labor markets by providing an alternative pathway for teachers to enter the labor force. Because the fixed costs to participating in the charter sector are low, teachers are able to explore their taste for teaching before committing to fixed costs (licenses). This in turn generates positive selection on the quality of teachers entering public school careers. Consistent with our model's 
predictions, we show that charter schools tend to hire unlicensed teachers who are ineligible to teach in the public sector and then there emerges a mobility pattern such that the least effective charter school teachers are more likely to exit teaching while effective teachers are more likely to obtain a license and move into the traditional public school sector. This pattern of results suggests that charter schools create a positive externality for local public schools by increasing the average quality of the labor available to them.

\section{References}

Abdulkadiroglu, A., Angrist, J. D., Dynarski, S. M., Kane, T. J., \& Pathak, P. A. (2011). Accountability and flexibility in public schools: Evidence from Boston's charters and pilots. The Quarterly Journal of Economics, 126(2):699-748. 3

Angrist, J. D., Hull, P. D., Pathak, P. A., \& Walters, C. R. (2017). Leveraging lotteries for school value-added: Testing and estimation. The Quarterly Journal of Economics, 132(2):871919. $2,12,13$

Angrist, J. D., Pathak, P. A., \& Walters, C. R. (2013). Explaining charter school effectiveness. American Economic Journal: Applied Economics, 5(4):1-27. 3, 7, 12, 15, 42

Bacher-Hicks, A., Chin, M. J., Kane, T. J., \& Staiger, D. O. (2019). An experimental evaluation of three teacher quality measures: Value-added, classroom observations, and student surveys. Economics of Education Review, 73(August):101919. 30

Bacher-Hicks, A., Kane, T. J., \& Staiger, D. O. (2014). Validating teacher effect estimates using changes in teacher assignments in los angeles. National Bureau of Econonomic Research. 2, 13, 14

Backes, B. \& Hansen, M. (2015). Teach for america impact estimates on nontested student outcomes. National Center for Analysis of Longitudinal Data in Education Research. 1

Baker, B. D. \& Dickerson, J. L. (2006). Charter schools, teacher labor market deregulation, and teacher quality. Educational Policy, 20(5):752-778. 3

Ballou, D. \& Podgursky, M. (1997). Teacher pay and teacher quality. W.E. Upjohn Institute for Employment Research, Kalamazoo, MI. 1

Bettinger, E. P. (2005). The effect of charter schools on charter students and public schools. Economics of Education Review, 24(2):133-147. 35 
Bifulco, R. \& Ladd, H. F. (2006). The impacts of charter schools on student achievement: evidence from north carolina. Education Finance and Policy, 1(1):50-90. 3, 35

Booker, K., Gilpatric, S. M., Gronberg, T., \& Jansen, D. (2007). The impact of charter school attendance on student performance. Journal of Public Economics, 91(5-6):849-876. 3

Booker, K., Gilpatric, S. M., Gronberg, T., \& Jansen, D. (2008). The effect of charter schools on traditional public school students in texas: Are children who stay behind left behind? Journal of Urban Economics, 64(1):123-145. 35

Bruhn, J. (2019). The consequences of sorting for understanding school quality. PhD thesis. 2,12

Carruthers, C. K. (2012). The qualifications and classroom performance of teachers moving to charter schools. Education and Finance Policy, 7(3):233-268. 4

Center for Research on Education Outcomes (2009). Multiple choice: Charter school performance in 16 states. Standford University. 4

Center for Research on Education Outcomes (2015). Urban charter school study: Report on 41 regions. Stanford University. 1

Chetty, R., Friedman, J. N., \& Rockoff, J. E. (2014a). Measuring the impacts of teachers I: evaluating bias in teacher value-added estimates. American Economic Review, 104(9):25932632. 2,13

Chetty, R., Friedman, J. N., \& Rockoff, J. E. (2014b). Measuring the impacts of teachers II: teacher value-added and student outcomes in adulthood. American Economic Review, 104(9):2633-2679. 6, 13, 14

Clark, M. a., Chiang, H. S., Silva, T., McConnell, S., Sonnenfeld, K., Erbe, A., Puma, M., Warner, E., \& Schmidt, S. (2013). The effectiveness of secondary math teachers from teach for america and the teaching fellows programs. U.S. Department of Education. 1

Clark, M. A., Gleason, P. M., Tuttle, C. C., \& Silverberg, M. K. (2015). Do charter schools improve student achievement? Educational Evaluation and Policy Analysis, 37(4):419436. 3

Cohodes, S., Setren, E., Walters, C., Dunn, S., Clark, J., Austin, W., Hall, A., \& Lehman, D. (2018). Can successful schools replicate? Scaling up boston's charter school sector. 
School Effectiveness \& Inequality Initiative, Massachusetts Instittue of Technology. 3, $12,14,15,44$

Cordes, S. A. (2018). In pursuit of the common good: The spillover effects of charter schools on public school students in New York City. Education Finance and Policy, 13(4):484512. 35

Cowen, J. M. \& Winters, M. A. (2013). Do charters retain teachers differently? Evidence from elementary schools in florida. Education Finance and Policy, 8(1):14-42. 1, 4, 12, 35

Deming, D. J. (2014). Using school choice lotteries to test measures of school effectiveness. American Economic Review: Papers \& Proceedings 2014, 104(5):406-411. 2, 13

Dobbie, W. \& Fryer, R. G. (2013). Getting beneath the veil of effective schools: Evidence from New York City. American Economic Journal: Applied Economics, 5(4):28-60. 3, 12

Efron, B. (2010). Large-scale inference: Empirical bayes methods for estimation, testing, and prediction. Cambridge University Press. 15

Feng, L. (2010). Hire today, gone tomorrow: New teacher classroom assignments and teacher mobility. Education Finance and Policy, 5(3):278-316. 3

Feng, L. \& Sass, T. R. (2017). Teacher quality and teacher mobility. Education Finance and Policy, 12(3):396-418. 3

Goldhaber, D. \& Hansen, M. (2010). Using performance on the job to inform teacher tenure decisions. The American Economic Review, 100(2):250-255. 1, 35

Hoxby, C. M. (2002). Would school choice change the teaching profession? The Journal of Human Resources, 37(4):846. 1

Hoxby, C. M. (2003). School choice and school competition: evidence from the united states. Swedish Economic Policy Review, 10:11-67. 35

Imberman, S. A. (2011a). Achievement and behavior in charter schools: Drawing a more complete picture. Review of Economics and Statistics, 93(2):416-435. 3

Imberman, S. A. (2011b). The effect of charter schools on achievement and behavior of public school students. Journal of Public Economics, 95(7-8):850-863. 35 
Jabbar, H., Castro, A., \& Germain, E. (2019). To switch or not to switch? The influence of school choice and labor market segmentation on teachers' job searches. Educational Evaluation and Policy Analysis, 41(3):375-399. 4

Jackson, C. K. (2012). School competition and teacher labor markets: Evidence from charter school entry in north carolina. Journal of Public Economics, 96(October):431-448. 3, 4

Jackson, C. K. (2013). Match quality, worker productivity, and worker mobility: Direct evidence from teachers. Review of Economics and Statistics, 95(4):1096-1116. 3

Jacob, B. A. \& Lefgren, L. (2008). Can principals identify effective teachers? Evidence on subjective performance evaluation in education. Journal of Labor Economics, 26(1):101136. 30

Kane, T. J., Rockoff, J. E., \& Staiger, D. O. (2008). What does certification tell us about teacher effectiveness? Evidence from New York City. Economics of Education Review, 27(6):615-631. 1

Kane, T. J. \& Staiger, D. O. (2008). Estimating teacher impacts on student achievement: An experimental evaluation. National Bureau of Economic Research. 2, 13

Koedel, C., Mihaly, K., \& Rockoff, J. E. (2015). Value-added modeling: A review. Economics of Education Review, 47:180-195. 2, 13, 14

Kukla-Acevedo, S. (2009). Leavers, movers, and stayers: The role of workplace conditions in teacher mobility decisions. The Journal of Educational Research, 102(6):443-452. 3

Loeb, S., Kalogrides, D., \& Béteille, T. (2012). Effective schools: Teacher hiring, assignment, development, and retention. Education Finance and Policy, 7(3):269-304. 3, 12, 18

Sass, T. R. (2006). Charter schools and student achievement in florida. Education Finance and Policy, 1(1):91-122. 3

Silverman, B. (1986). Density estimation for statistics and data analysis. Chapman and Hall. 43,47

Staiger, D. O. \& Rockoff, J. E. (2010). Searching for effective teachers with imperfect information. Journal of Economic Perspectives, 24(3):97-118. 1, 35 
Stein, C. (1956). Inadmissibility of the usual estimator for the mean of a multi-variate normal distribution. In Jerzy Neyman, editor, Proceedings of the Third Berkeley Symposium on Mathematical Statistics and Probability, pages 197-206. 15

Strunk, K. O. (2011). Are teachers' unions really to blame? Collective bargaining agreements and their relationships with district resource allocation and student performance in california. Education Finance and Policy, 6(3):354-398. 3

Stuit, D. A. \& Smith, T. M. (2012). Explaining the gap in charter and traditional public school teacher turnover rates. Economics of Education Review, 31(2):268-279. 4

Winters, M. A. (2012). Measuring the effect of charter schools on public school student achievement in an urban environment: Evidence from New York City. Economics of Education Review, 31(2):293-301. 35 


\section{Intended for Online Publication Only}

\section{A Data Appendix}

\section{A.1 SIMS Data}

The SIMS data comes from information transmitted from school districts to the state of Massachusetts. The data is reported to the state three times per year. The data was provided to us in the form of 27 separate SPSS .sav files, each one corresponding to one of the the three reporting periods over the course of the 9 years this study spans. We used only the information as reported in spring of the relevant academic year. The unit of observation in these data files is the student. After standardizing variable names to be common across years, we merged the files to generate a panel data set at the student-year level. From there, we resolved inconsistencies in the labeling of the data. For example, the gender variable sometimes coded males as "M" and others as "m"; we ensured such coding was common across all years.

\section{A.2 MCAS and PARCC Data}

The state of Massachusetts provided MCAS data for the spring test administration spanning the years 2008 through 2016. This data was transmitted to us in nine separate SPSS .sav files, one for each year for the relevant period. In 2015 and 2016, the state piloted a next generation assessment based on the Partnership for Assessment of Readiness for College Careers (PARCC) standard. For this reason, the 2015 and 2016 data files that we initially received were missing a large number of student test scores. DESE then sent us two additional files which contained the missing scores. After standardizing variable names across years, we merged the files into a panel data set at the student-year level.

For the years 2008-2014, we use raw MCAS scores and standardize them within year and grade to have mean 0 and standard deviation 1. For the years 2015 and 2016, some students in the state took PARCC, some took MCAS, and others took both. For these years, we take the raw MCAS scores wherever available. The state was unable to locate raw PARCC scores for this study. For the 2015 test we used PARCC to MCASS concordance scores and for the 2016 test, we used PARCC theta scores, which are transformed versions of the raw scores meant to adjust for question difficulty using techniques from item response theory. Within each of these years, we standardized the test scores at the test-type (raw MCAS, PARCC concordance, PARCC theta) and grade level to have mean 0 and standard deviation 1 . In addition, we control 
for test types (raw MCAS, PARCC concordance, PARCC theta) in the relevant teacher and school value-added specifications.

\section{A.3 EPIMS Data}

The EPIMS data comes from information transmitted from school districts to the state of Massachusetts. The data was provided to us in nine separate SPSS .sav files, each one corresponding to an academic year. The unit of observation in this data is a teacher-school-coursesection-term. After standardizing variable names, we merged the files into a single data set at the teacher-year-school-course-term level. From there, we resolved inconsistencies in the data. For example, the gender variable sometimes coded males as "M" and others as "m"; we ensured such coding was common across all years.

\section{A.4 SCS Data}

The SCS data come from information transmitted from school districts to DESE. It was provided to us in five separate SPSS .sav files, one file for each year from 2011-2016. Prior to 2011, the state did not collect data on student coursework. The unit of observation in this data is a student-school-course-section-term. After standardizing variable names, we merged the files into a single data set at the student-year-school-course-section-term level. This data came to us with consistent year-to-year coding and required virtually no cleaning after merging. The research assistant working on this project was very excited about this development.

\section{B Validating Teacher VAM}

Figure B.1 plots the distribution of our school value added estimates. Reassuringly, our school value-added estimates are consistent with the lottery based estimates from Angrist et al. (2013) which examine charter school impacts inside and outside urban areas. We find that Boston charter schools generate larger test score gains than their public school counterparts within the city. However, outside of Boston, charter schools show little advantage in math and even value-added that is slightly lower than traditional schools in ELA.

Figure B.2 plots the distribution of within-school teacher value-added by sector for the entire state of Massachusetts over the relevant time period. We find that, averaging across all schools in each sector, the variance of the within-school distributions of teacher value-added is slightly lower for the traditional public sector ( $\sigma=0.147$ for math and $\sigma=0.132$ for ELA) than it is for the charter school sector ( $\sigma=0.153$ for math and $\sigma=0.144$ for ELA). 


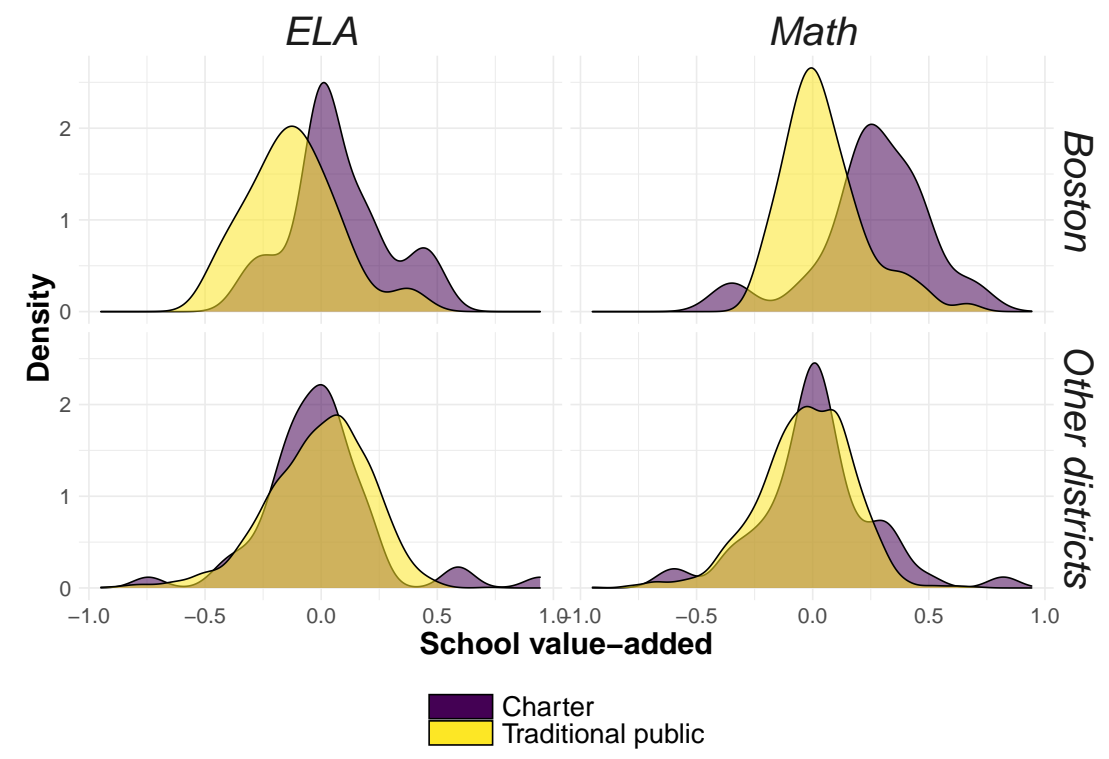

FIGURE B.1: Distribution of School Value-Added

Note: The distributions in this figure are created using the school value-added estimates recovered from the mixed effects model outlined in Equation (3). We use a Gaussian kernel and choose the bandwidth according to Silverman's rule (Silverman, 1986) which is a robust version of the optimal bandwidth under normality.

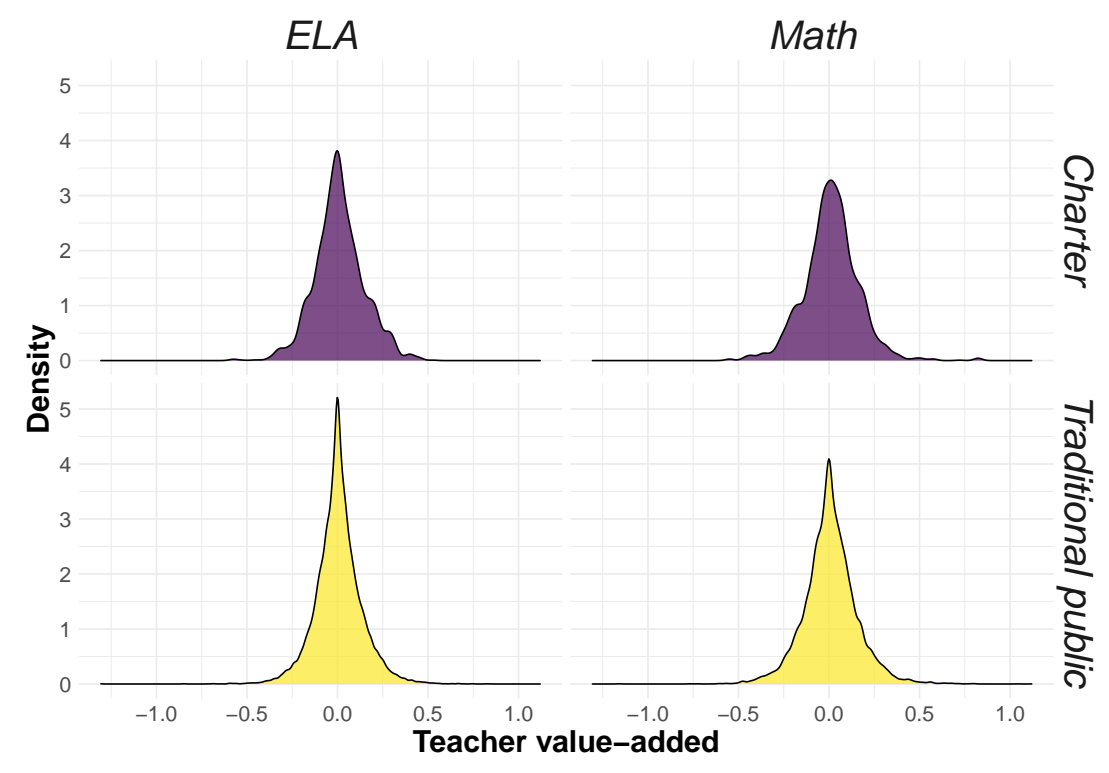

FIGURE B.2: Distribution of Teacher Value-Added within Schools

Note: The distributions in this figure are created using the teacher value-added estimates recovered from the mixed effects model outlined in Equation (3). We use a Gaussian kernel and choose the bandwidth according to Silverman's rule (Silverman, 1986) which is a robust version of the optimal bandwidth under normality. 


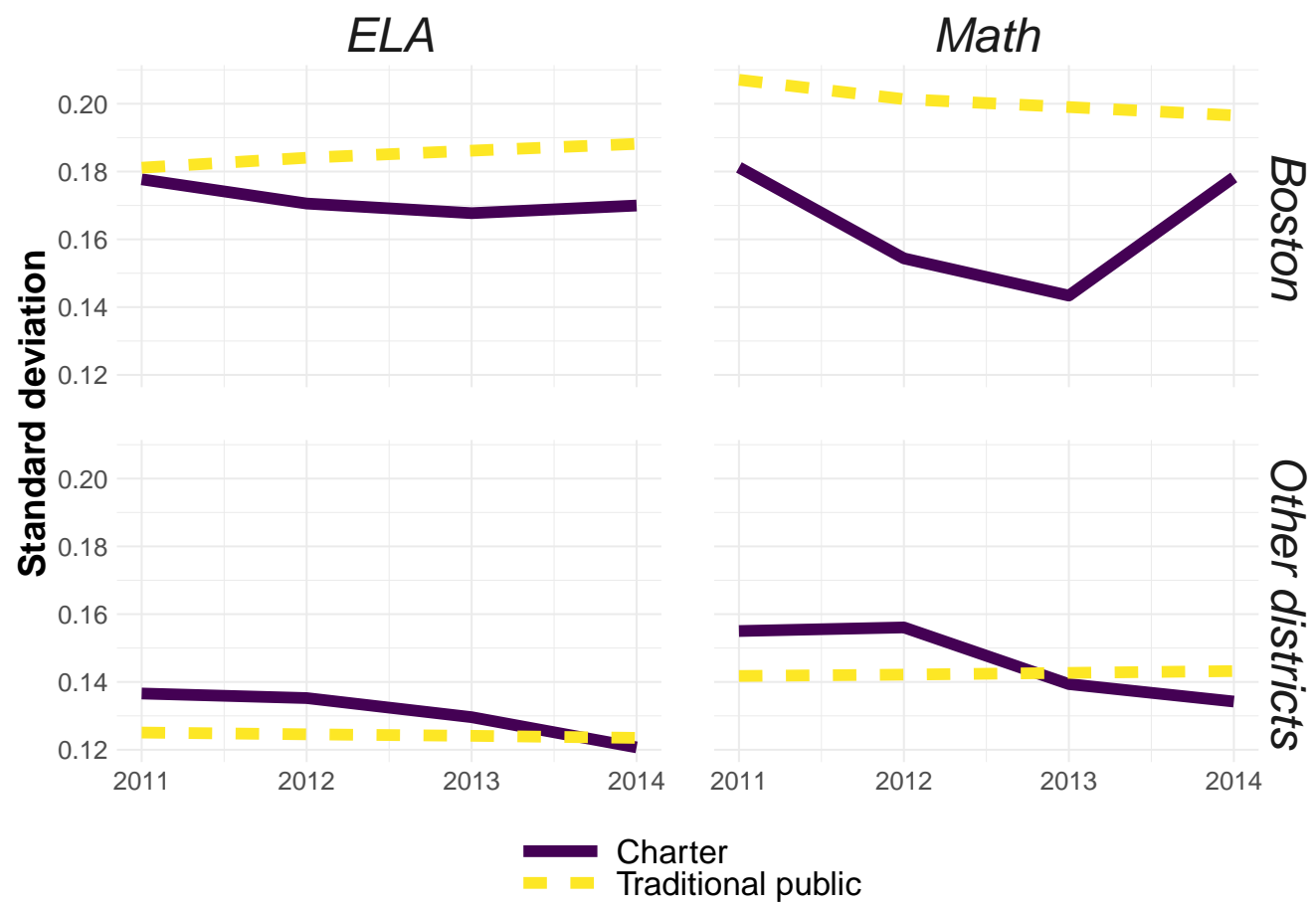

FIGURE B.3: Standard Deviation of Teacher Value-Added

Note: This figure plots the standard deviation of teacher value-added over time in charter and traditional public schools for both the Boston school district and the rest of the state.

However, within Boston, we find that the variance of teacher effects in the charter school sector is substantially lower in math than it is in the traditional public sector, with smaller differences for ELA. Figure B.3 plots the standard deviation of within school value-added in Boston and the rest of the state from 2011-2014, which is the period of time where Cohodes et al. (2018) are able to estimate teacher value-added in Boston. Our value-added model partially replicates the findings from Cohodes et al. (2018) that Boston charter schools have smaller variance of teacher effects than the Boston public schools. The fact that our results for ELA differ slightly from Cohodes et al. (2018) may be due to the use of different value-added estimation methods across papers or from differences in the construction of the sample. ${ }^{20}$ Notably, their model includes classroom and school random effects whereas we model the school effect as fixed and do not include classroom effects. However, the broad conclusions are the same across papers.

\footnotetext{
${ }^{20}$ For example, we include all teachers in Grades 4-8, while they limit their analysis to middle school.
} 


\section{Estimation Details and Robustness}

\section{C.1 Bootstrap Details}

Recall that all of our primary specifications involve estimation in three stages as described in 2.2. First we estimate test score residuals within teacher:

$$
y_{i j s t}=\delta_{j s}+\rho X_{i s t}+\epsilon_{i j s t}
$$

Where $y_{i j s t}$ is the test score of student $i$ assigned to teacher $j$ at school $s$ in academic year $t, \delta_{j s}$ is a teacher by school fixed effect, and $X_{i s t}$ is the vector of controls detailed in the body of the paper. We then construct test score residuals:

$$
\tilde{y}_{i j s t}=y_{i j s t}-\hat{\rho} X_{i s t} \approx \delta_{j s}+\epsilon_{i j s t}
$$

and estimate the following correlated random effects model:

$$
\tilde{y}_{i j s t}=\omega_{s}+\delta_{j s}+u_{i j s t}
$$

Where $\omega_{s}$ is fixed and $\delta_{j s}$ is random.

We then take the the teacher and school value-added measures from this model, and typically estimate models of the following form:

$$
d_{j s t}=f\left(\hat{\delta}_{j s}, \hat{\omega}_{s} ; \beta\right)+\eta_{j s t}
$$

Where $d_{j s t}$ are indicators for whether teacher $j$ made some kind of labor market transition relative to school $s$ at time $t$. The particular function $f()$ we specify varies from application to application as detailed in the main body of the text. To perform inference correctly for Equation (11), we need to account for the extra variability that is induced when we estimate Equations (8) and (10). We do this via a parametric bootstrap.

Let $\left\{\hat{\delta}_{j}\right\}_{j \in J}=\hat{\delta}$ and $\left\{\hat{\omega}_{s}\right\}_{s \in S}=\hat{\omega}$, and make the standard distributional assumptions necessary for inference on these parameters:

$$
\begin{gathered}
\hat{\delta} \sim \mathbb{N}\left(\delta, \Sigma_{J}\right) \\
\hat{\omega} \sim \mathbb{N}\left(\omega, \Sigma_{S}\right)
\end{gathered}
$$

Where $\Sigma_{S}$ and $\Sigma_{J}$ are variance-covariance matrices. 
After estimating $\hat{\Sigma}_{S}$ and $\hat{\Sigma}_{J}$ via standard methods that account for heteroskedactitiy by clustering at the appropriate level, the bootstrap algorithm proceeds as follows:

1. Draw a bootstrap sample of teachers from the data (indexed by $n$ ) and also draw their corresponding value-added estimates $(\tilde{\delta})_{n}$ from the distribution in Equations (12) using the estimated means and variance-covariance matrix.

2. Draw a vector of school-value added estimates $(\tilde{\omega})$ from the distribution in Equations (13) using the estimated means and variance-covariance matrix.

3. Estimate Equation (11) using the bootstrap sample $(\tilde{\delta}, \tilde{\omega})_{n}$ in place of the true values and record the parameter of interest $\tilde{\beta}_{n}$.

4. Repeat steps 1 and 2 for $n \in N=\{1 \ldots N\}$. In practice, we set $N$ equal to 10,000 .

5. Calculate the relevant test statistics from the bootstrap distribution:

$$
\hat{F}_{\hat{\beta}}(\beta)=\frac{1}{N} \sum_{n \in N} \mathbb{1}(\beta<\tilde{\beta})
$$

\section{C.2 Extending the Primary Results Beyond 7 Years-in-District}

In this section, we present results calculated identically to Figure 1, but for teachers with greater than 7 years in district. First, to motivate the sample restrictions we imposed in the main body of the text, we present a histogram of teachers by years in district for the charter school and public sectors.

As is clear from Figure C.1, the support of the years-in-district variable is very different across the two sectors. There are 1,134 charter observations (451 distinct teachers) with 3-7 years in district; in the traditional public sector, there are 21,792 observations $(7,881$ distinct teachers). By way of contrast, there are only 444 charter observations (176 distinct teachers) with 8-11 years in district, and 298 charter observations (88 distinct teachers) with 12+ years in district. The comparable numbers in the traditional public sector are 18,306 (6,840 distinct teachers) for 8-11 years in district and 35,910 (7,158 distinct teachers) for 12+ years in district.

With these facts in mind, Figure C.2 presents results for teachers with greater than 7 years in district. The results are similar to those presented in the main body of the text, but as expected from the sample sizes, the charter estimates are less precise. 


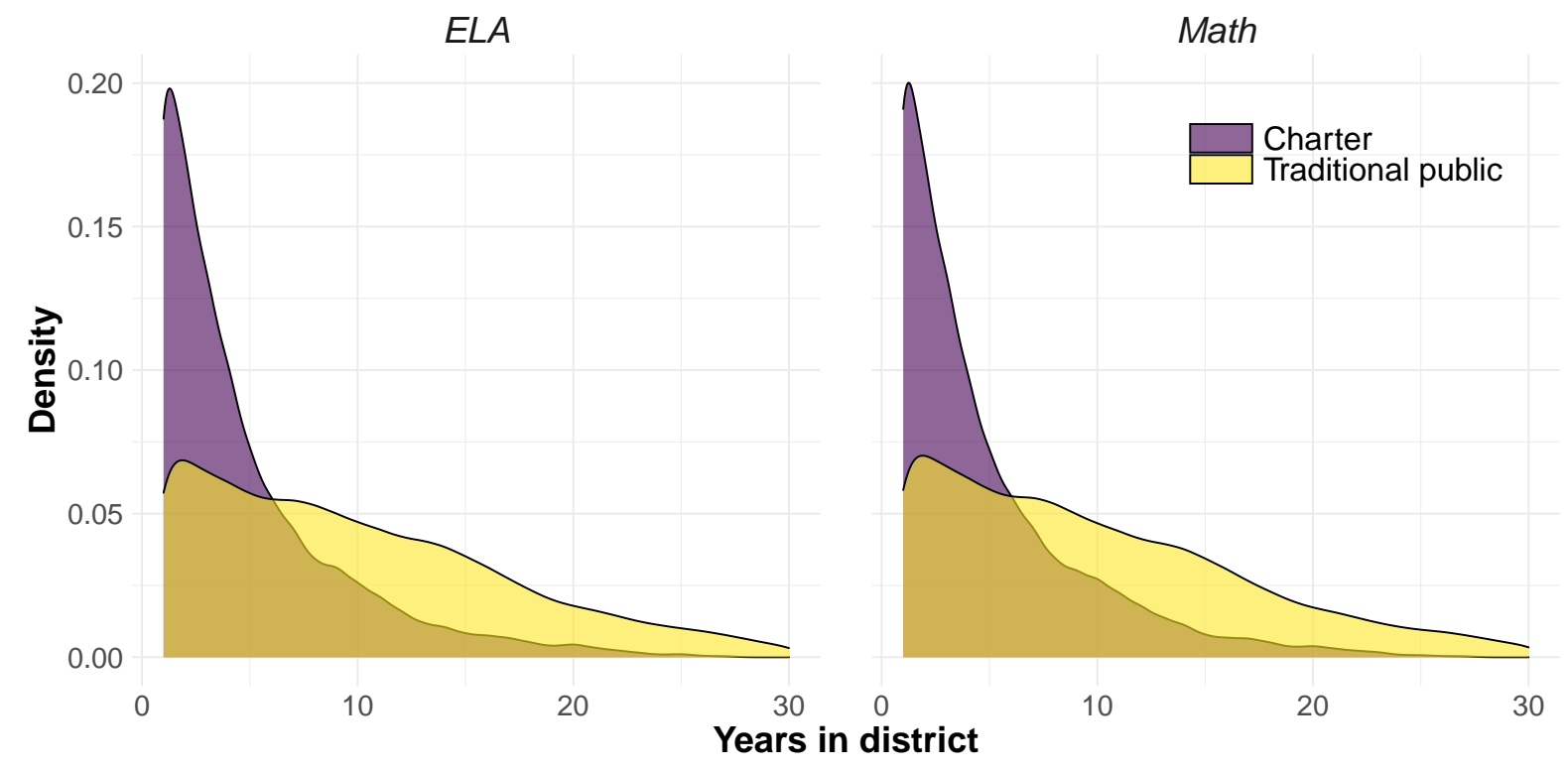

\section{FiguRE C.1: Density of Years in District}

Note: This figure plots estimates of the probability density function for the number of years-in-district for both math and ELA teachers in the charter and traditional public sectors. We use a Gaussian kernel and choose the bandwidth according to Silverman's rule (Silverman, 1986) which is a robust version of the optimal bandwidth under normality.

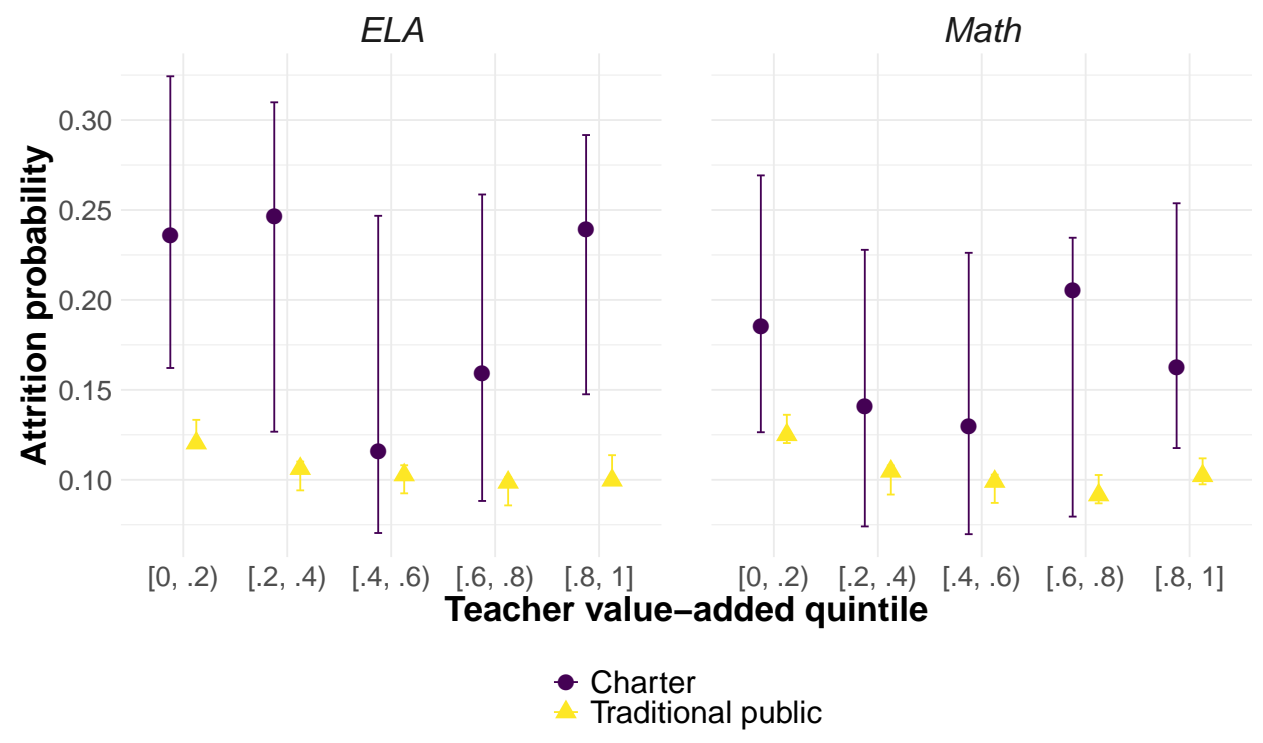

FigURE C.2: Attrition and Teacher Value-Added: Greater than 7 Years Tenure

Note: This figure documents how teacher attrition varies with teacher value-added for both math and ELA teachers with greater than 7 years in district. "Attrit" takes a value of 1 if the teacher is employed in school $s$ at time $t$ but not at time $t+1$. The x-axis plots quintiles of the within sector distribution of teacher value-added. Dots are conditional means for the sample of charter school teachers. Triangles are conditional means for the sample of traditional public school teachers. Vertical bars represent $95 \%$ confidence intervals. 


\section{C.3 Results Outside of Boston}

In this section, we show that the relationship in figure 1 continues to hold if we restrict attention only to charter and public schools outside of Boston. Thus it does not appear that our results are being driven by an urban-suburban or an urban-rural divide in attrition patterns.

\section{C.4 A More Restrictive Definition of High-and Low-Quality Schools}

In this section, we present results that are identical to those shown in Figure 3 except that we use a more restrictive definition of "high" and "low" quality schools. In Figure 3 a high-quality school is one that fell within the top two quintiles of the within sector distribution of school value-added, and a low-quality school fell within the bottom two quintiles. In figure C.4 we restrict high-and low-quality schools to reflect the top and bottom quintile respectively. The broad take aways are similar.

\section{C.5 Differential Attrition by School Value-Added Across Subjects}

In this section, we present results that are identical to those shown in Figure 3 except that we produce the figure separately for ELA teachers.

\section{C.6 Attrition Decomposition for ELA Teachers}

In this section, we present results that are identical to Figure 5 except that we use ELA teachers instead of math teachers. The results are broadly similar, with the exception being that, among experienced teachers, high value-added teachers in charter schools are also significantly more likely to exit the profession.

\section{Solving the Model}

\section{Period 2}

Observe that if a teacher does not work in period 1, they will not work in period 2. Thus at the start of period 2, there are two types of teachers: those who have licenses and those who worked in a charter school last period.

For teachers with licenses, they will choose work in a traditional public school if $\mathbb{E}(u \mid p)>$ $\mathbb{E}(u \mid c)$ and $\mathbb{E}(u \mid p)>0$ and which reduces to the following conditions: 


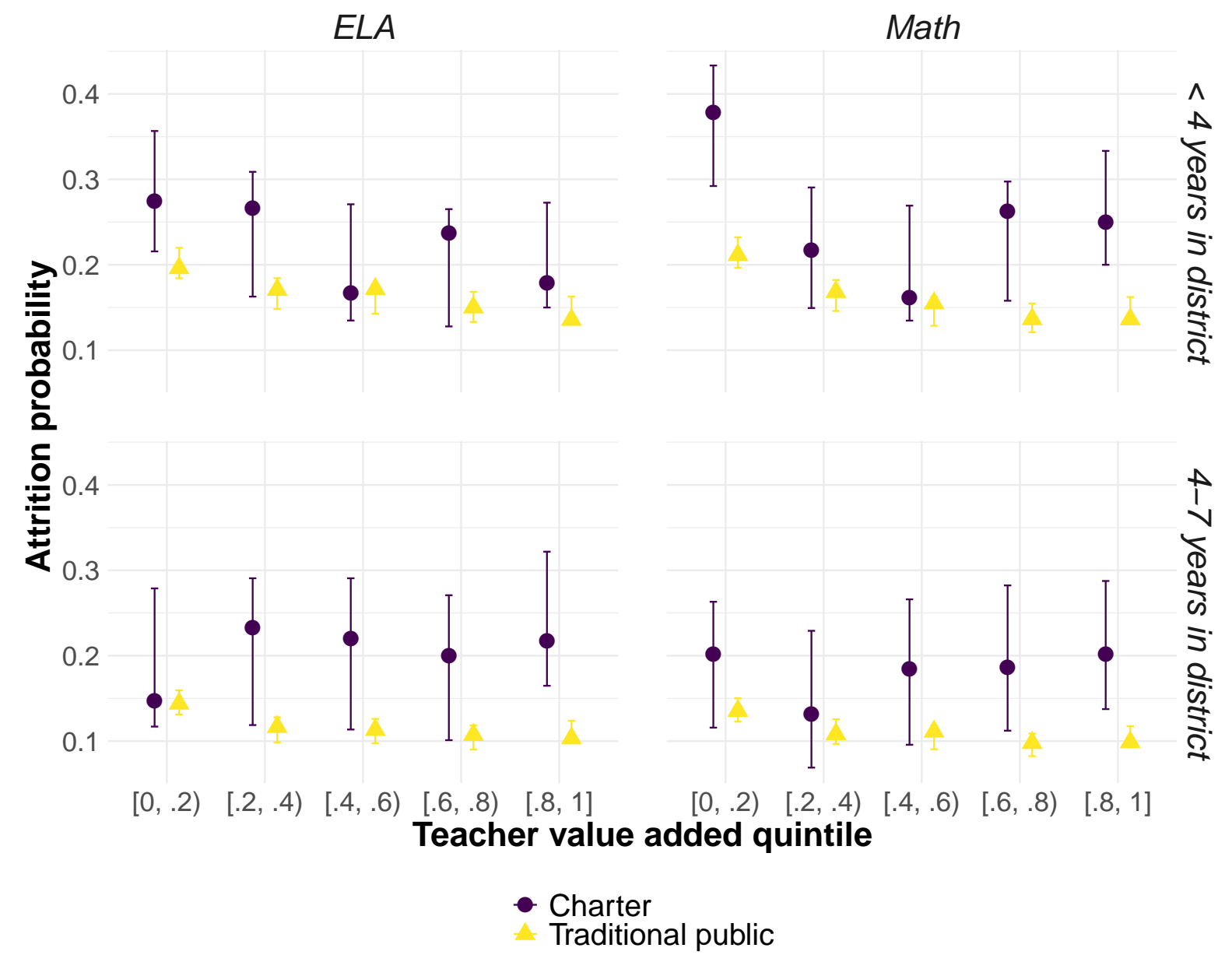

FiguRE C.3: Attrition and Teacher Value-Added Outside of Boston

Note: This figure documents how teacher attrition varies with teacher value-added for both math and ELA teachers. "Attrit" takes a value of 1 if the teacher is employed in school $s$ at time $t$ but not at time $t+1$. " $<4$ years in district" refers to teachers who have been employed in their current district less than 4 years. "4-7 years in district" refers to teachers who have been employed in their current district not less than 4 but no more than 7 years. The x-axis plots quintiles of the within sector distribution of teacher value-added. Dots are conditional means for the sample of charter school teachers. Triangles are conditional means for the sample of traditional public school teachers. Vertical bars represent $95 \%$ confidence intervals. 
Bottom 20\%
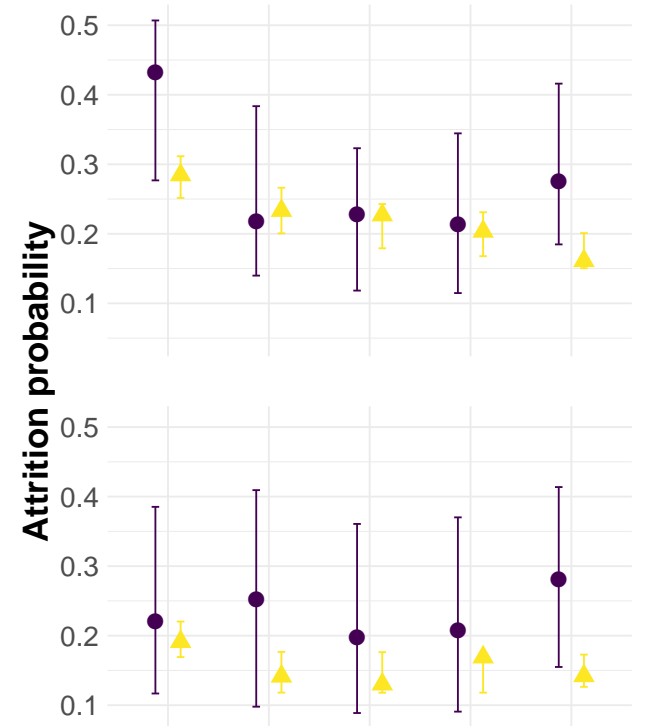

$[0, .2) \quad[.2, .4)[.4, .6) \quad[.6, .8) \quad[.8,1]$
Upper 20\%
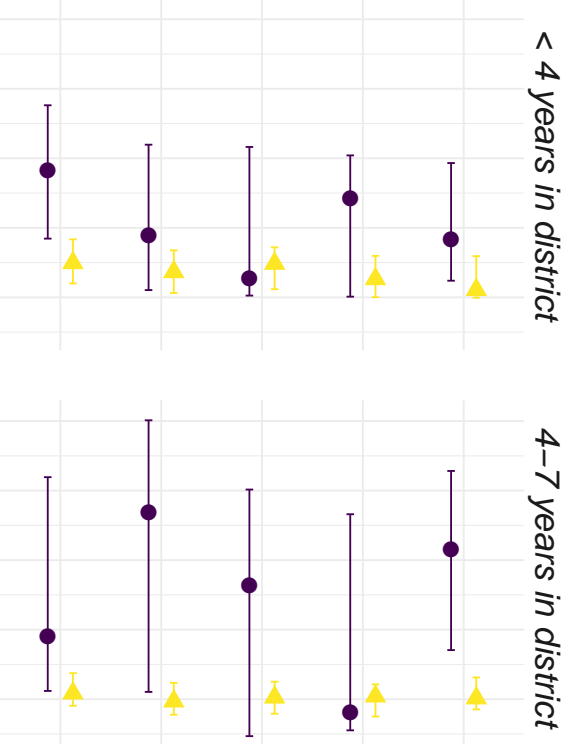

$[0, .2) \quad[.2, .4) \quad[.4, .6) \quad[.6, .8) \quad[.8,1]$

\section{$\frac{\sqrt{2}}{3}$}

$\frac{\sqrt{2}}{2}$

Teacher value added quintile

- Charter

Traditional public

\section{FigURE C.4: School Value-Added (Restrictive), Teacher Value-Added, and Attrition by Sec-} tor

Note: This figure documents how the differential relationship between attrition and teacher quality across sectors varies with the quality of schools, pooling both math and ELA teachers for power. "Attrit" takes a value of 1 if the teacher is employed in school $s$ at time $t$ but not at time $t+1$. "< 4 years in district" refers to teachers who have been employed in their current district less than 4 years. "4-7 years in district" refers to teachers who have been employed in their current district not less than 4 but no more than 7 years. "Bottom 20\%" refers to schools in the bottom quintile of the within-sector distribution of estimated school value-added. "Upper 20\%" refers to schools in the top quintile of the within-sector distribution of estimated school value-added. The $\mathrm{x}$-axis plots quintiles of the within sector distribution of teacher value-added. Dots are conditional means for the sample of charter school teachers. Triangles are conditional means for the sample of traditional public school teachers. Vertical bars represent $95 \%$ confidence intervals. 


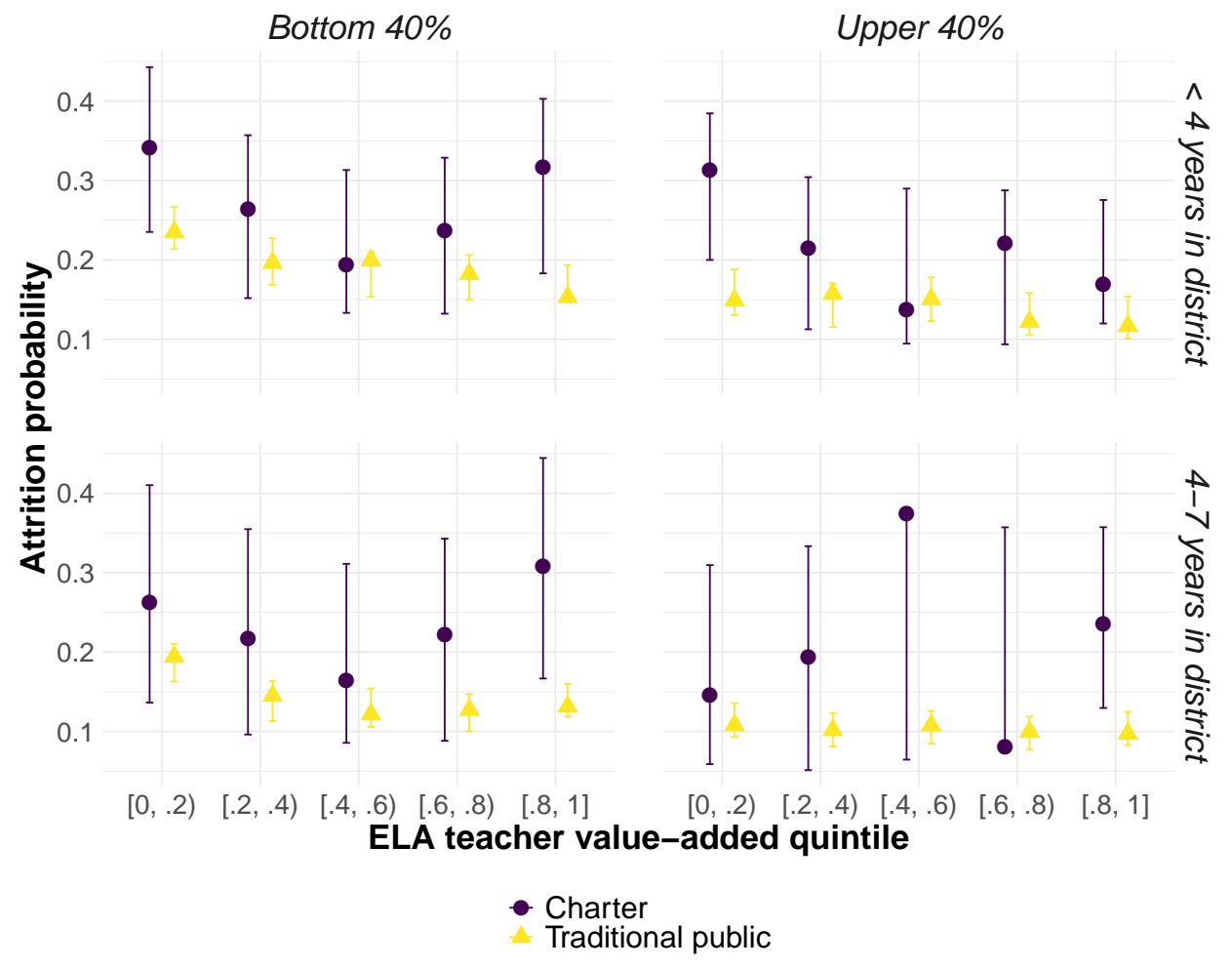

\section{FiguRE C.5: School Value-Added, ELA Teacher Value-Added, and Attrition by Sector}

Note: This figure documents how the differential relationship between attrition and teacher quality across sectors varies with the quality of schools for ELA teachers. "Attrit" takes a value of 1 if the teacher is employed in school $s$ at time $t$ but not at time $t+1$. " $<4$ years in district" refers to teachers who have been employed in their current district less than 4 years. "4-7 years in district" refers to teachers who have been employed in their current district not less than 4 but no more than 7 years. "Bottom $40 \%$ " refers to schools in the bottom quintile of the within-sector distribution of estimated school value-added. "Upper 40\%" refers to schools in the top quintile of the within-sector distribution of estimated school value-added. The x-axis plots quintiles of the within-sector distribution of teacher value-added. Dots are conditional means for the sample of charter school teachers. Triangles are conditional means for the sample of traditional public school teachers. Vertical bars represent $95 \%$ confidence intervals. 


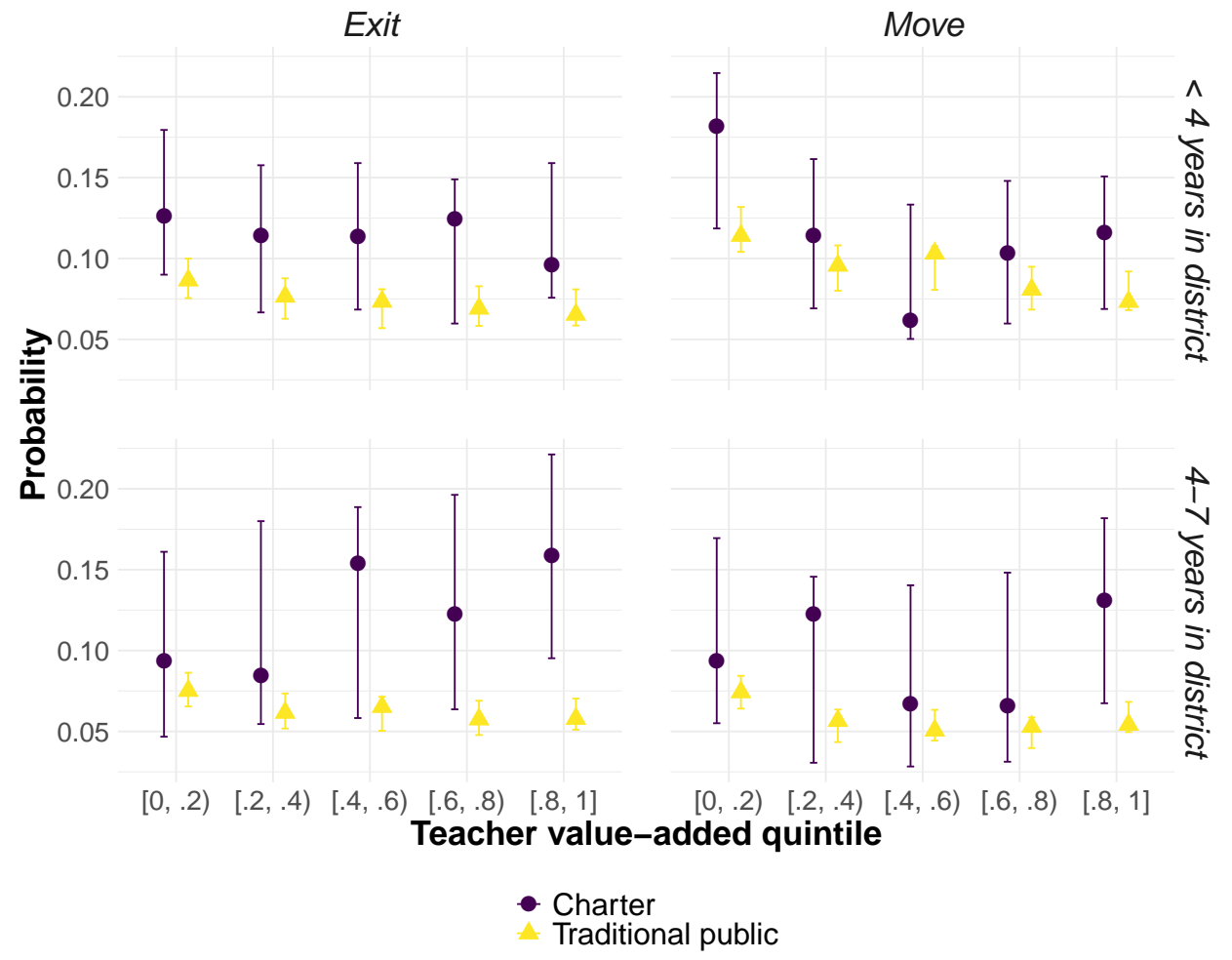

Figure C.6: Exits versus Moves for ELA Teachers

Note: This figure decomposes the differential relationship between attrition and ELA teacher value-added across sectors into different attrition types. "Move" takes a value of 1 if a teacher attrits at time $t$ but is employed as a teacher in some other school in our data as of time $t+1$. "Exit" takes a value of 1 if the teacher attrits time $t$ but does not work as a teacher in any public school in Massachusetts as of time $t+1$. " $<4$ years in district" refers to teachers who have been employed in their current district less than 4 years. "4-7 years in district" refers to teachers who have been employed in their current district not less than 4 but no more than 7 years. The x-axis represents quintiles of the within sector distribution of teacher value-added. Dots are conditional means for the sample of charter school teachers. Triangles are conditional means for the sample of traditional public school teachers. Vertical bars represent $95 \%$ confidence intervals. 


$$
\begin{aligned}
w_{p} & >w_{c} \\
\theta+w_{p} & >\chi
\end{aligned}
$$

Similarly, for teachers who are unlicensed, they will obtain a license and work in a traditional public school if:

$$
\begin{aligned}
& w_{p}-w_{c}>k \\
& \theta+w_{p}>\chi+k
\end{aligned}
$$

And teachers will work in a charter school if:

$$
\begin{gathered}
w_{p}-w_{c}<k \\
\theta+w_{c}>\chi
\end{gathered}
$$

Finally, the remaining teachers leave the labor force.

\section{Period 1}

We now calculate the expected utility of obtaining licensure versus working in the charter sector for different values of the cost $k$. Let $v_{\ell}=v_{\ell}(\theta, k)$ be the discounted value of utility over both periods for a teacher of type $(\theta, k)$ if they obtain a license at time 1 , and let $v_{0}$ be the discounted value of utility if they do not. We will focus on equilibria such that $w_{p}>w_{c}$. This ensures that once the teacher knows their type, they would rather be in a public school than a charter school (conditional on working).

Observe that for any value of $k$, the expected benefit to obtaining a license now and working in a public school is:

$$
\begin{aligned}
\mathbb{E}\left(v_{\ell}\right) & =P\left(\theta>\chi-w_{p}\right)(1+\rho)\left(w_{p}+\bar{\theta}_{\theta>\chi-w_{p}}-\chi\right) \\
& =\left(1-\chi+w_{p}\right)(1+\rho)\left(w_{p}+\frac{1+\chi-w_{p}}{2}-\chi\right) \\
& =\frac{1}{2}(1+\rho)\left(1-\chi+w_{p}\right)^{2}
\end{aligned}
$$


Next observe that for $k$ such that $w_{p}-w_{c}<k$ (i.e., if the teacher enters the second period unlicensed, they would not want to buy one for any value of $\theta$ ), the expected utility to going unlicensed and working in a charter is:

$$
\begin{aligned}
\mathbb{E}\left(v_{0} \mid w_{p}-w_{c}<k\right) & =w_{c}+\bar{\theta}-\chi+\rho P\left(\theta>\chi-w_{c}\right)\left(w_{c}+\bar{\theta}_{\theta>\chi-w_{c}}-\chi\right) \\
& =w_{c}+.5-\chi+\frac{\rho}{2}\left(1-\chi+w_{c}\right)^{2}
\end{aligned}
$$

Thus a teacher will buy a license in the first period if:

$$
\begin{gathered}
\mathbb{E}\left(v_{\ell}\right)-\mathbb{E}\left(v_{0} \mid w_{p}-w_{c}<k\right)>k \\
\mathbb{E}\left(v_{\ell}\right)>k
\end{gathered}
$$

From there we can define a threshold:

$$
k^{*}\left(w_{c}\right)=\mathbb{E}\left(v_{\ell}\right)-\mathbb{E}\left(v_{0} \mid w_{p}-w_{c}<k\right)
$$

Such that a teacher will obtain a license in the first period if $w_{p}-w_{c}<k<k^{*}$. Observe that the mass of teachers with $\theta+w_{p}>\chi$ will work in a TPS for two periods; otherwise, they exit the labor force immediately. For teachers with $k>k^{*}$, they will work in a charter if $\mathbb{E}\left(v_{0} \mid w_{p}-w_{c}<k\right)>0$, and otherwise they will never enter the labor force. Observe that those teachers with $\theta+w_{c}>\chi$ will become "career" charter teachers in the sense that they work in this sector for both periods; the rest leave the labor force in period 2.

Next observe that for $k$ such that $w_{p}-w_{c}>k$ (i.e., if the teacher works next period, they will want to buy a license and work in a public school), the expected utility to going unlicensed is:

$$
\begin{aligned}
\mathbb{E}\left(v_{0} \mid w_{p}-w_{c}>k\right) & =w_{c}+\bar{\theta}-\chi+\rho P\left(\theta>\chi+k-w_{p}\right)\left(w_{p}+\bar{\theta}_{\theta>\chi}+k-w_{p}-\chi-k\right) \\
& =w_{c}+.5-\chi+\rho\left(1-\chi-k+w_{p}\right)\left(w_{p}+\frac{1+\chi+k-w_{p}}{2}-\chi-k\right) \\
& =w_{c}+.5-\chi+\frac{\rho}{2}\left(1-\chi+w_{p}\right)^{2}+\frac{\rho}{2} k^{2} \\
& =\mathbb{E}\left(u_{c}\right)+\rho P\left(\theta>\chi-w_{p}\right) \mathbb{E}\left(u_{p} \mid \theta>\chi-w_{p}\right)+\frac{\rho}{2} k^{2}
\end{aligned}
$$


From there, we observe that a teacher will buy a license if:

$$
\begin{array}{r}
\mathbb{E}\left(v_{\ell}\right)-\mathbb{E}\left(v_{0} \mid w_{p}-w_{c}>k\right)>k \\
\frac{1}{2}\left(1-\chi+w_{p}\right)^{2}-\left(w_{c}+.5-\chi\right)>k+\frac{\rho}{2} k^{2} \\
P\left(\theta>\chi-w_{p}\right) \mathbb{E}\left(u_{p} \mid \theta>\chi-w_{p}\right)-\mathbb{E}\left(u_{c}\right)>k+\frac{\rho}{2} k^{2}
\end{array}
$$

Let $\delta\left(w_{c}\right)$ be the determinant of the polynomial $\frac{1}{2}\left(1-\chi+w_{p}\right)^{2}-\left(w_{c}+.5-\chi\right)-k+-\frac{\rho}{2} k^{2}$, and when it exists, let $\tilde{k}$ denote its positive root. Then we can define a second threshold:

$$
k^{\dagger}\left(w_{c}\right)= \begin{cases}0 & \delta\left(w_{c}\right)<0 \\ \max (\tilde{k}, 0) & \delta\left(w_{c}\right) \geq 0\end{cases}
$$

Observe that teachers with $k^{\dagger}<k<w_{p}-w_{c}$ will not obtain a license in period 1. Of that group, those who subsequently learn that $\theta>\chi-w_{p}$ will switch to the TPS sector and the rest will leave the labor force.

Teachers with $k<k^{\dagger}$ will obtain a license in period 1 . Those with $\theta>\chi-w_{p}$ will work in traditional public schools for two periods. The rest leave the labor force immediately.

\section{Calculating Charter Labor Supply}

Given the thresholds found in the last section, we can calculate the charter school's labor supply and average educator productivity in the first period as:

$$
\begin{aligned}
\mathbb{S}_{1} & =\max \left(w_{p}-w_{c}-k^{\dagger}, 0\right)+1-k^{*} \\
\bar{\theta}_{1} & =0.5
\end{aligned}
$$

And we can calculate charter school labor supply and average productivity in the second period as: 


$$
\begin{aligned}
& \mathbb{S}_{2}=\left(1-k^{*}\right) \min \left(1-\chi+w_{c}, 1\right) \\
& \bar{\theta}_{2}=\frac{1+\max \left(\chi-w_{c}, 0\right)}{2}
\end{aligned}
$$

Thus the charter school's maximization problem is:

$$
\max _{w_{c}} F\left(\mathbb{S}_{1} \times \bar{\theta}_{1}\right)+\delta F\left(\mathbb{S}_{2} \times \bar{\theta}_{2}\right)-w_{c}\left(\mathbb{S}_{1}+\delta \mathbb{S}_{2}\right)
$$

Which yields solution $w_{c}^{*}$.

\section{Numerical Example}

Suppose that:

$$
\begin{aligned}
w_{p} & =0.5 \\
\rho & =0.7 \\
\chi & =0.6 \\
\delta & =0.1 \\
F & =\sqrt{x}
\end{aligned}
$$

Then the charter wage $w^{*}=0.15$ is an equilibrium, and at this equilibrium, the supply of potential career charter teachers is 0.47 . Of those potential career teachers, $53 \%$ leave the labor force and have average quality of 0.27 ; those who remain have average quality of 0.725 . The mass of teachers exploring their option value by working in the charter sector in the first period is 0.085 . In the second period, $65 \%$ of those teachers switch to the public sector; they have average quality 0.70 . The rest have average quality of 0.13 and leave the labor force.

From there, we can calculate that, within the charter sector, the average value added of teachers who move to public schools is 0.7 , the average value-added of those who remain is 0.725 , and the average value-added of those who leave is 0.26 . Note that this does not match our pattern of facts completely, since the charter teachers most likely to remain come from the top of the distribution (rather than the middle). We could match this easily by allowing differential costs across sectors (i.e. $\chi_{c}$ and $\chi_{p}$ with $\chi_{p}>\chi_{c}$ ). However, we view the fact that top and 
bottom attrition emerges even without this source of heterogeneity as the primary feature of the model; hence, we show the simplest version in the paper to highlight the fact that the main margin driving top and bottom attrition is heterogeneous licensure costs creating option value.

\section{E Numerical Values for Key Figures}

TABLE E.1: Numerical Values for Figure 1

\begin{tabular}{|c|c|c|c|c|c|c|}
\hline Subject & Tenure category & School type & Value-added quintile & Attrition probability & $95 \%$ CI lower bound & $95 \%$ CI upper bound \\
\hline ELA & $<4$ years in district & Charter & {$[0, .2)$} & 0.30808081 & 0.24019608 & 0.3596059 \\
\hline ELA & $<4$ years in district & Charter & {$[.2, .4)$} & 0.22797927 & 0.16410256 & 0.2864322 \\
\hline ELA & $<4$ years in district & Charter & {$[.4, .6)$} & 0.17525773 & 0.14494444 & 0.2604388 \\
\hline ELA & $<4$ years in district & Charter & {$[.6, .8)$} & 0.22797927 & 0.14672490 & 0.2642789 \\
\hline ELA & $<4$ years in district & Charter & {$[.8,1]$} & 0.21212121 & 0.17097144 & 0.2791878 \\
\hline ELA & $<4$ years in district & TPS & {$[0, .2)$} & 0.20053050 & 0.18860082 & 0.2234987 \\
\hline ELA & $<4$ years in district & TPS & {$[.2, .4)$} & 0.17215728 & 0.15093358 & 0.1866470 \\
\hline ELA & $<4$ years in district & TPS & {$[.4, .6)$} & 0.17650186 & 0.14555964 & 0.1800118 \\
\hline ELA & $<4$ years in district & TPS & {$[.6, .8)$} & 0.14984060 & 0.13498755 & 0.1693046 \\
\hline ELA & $<4$ years in district & TPS & {$[.8,1]$} & 0.13853503 & 0.13397911 & 0.1649867 \\
\hline ELA & 4-7 years in district & Charter & {$[0, .2)$} & 0.18691589 & 0.13761468 & 0.2882883 \\
\hline ELA & 4-7 years in district & Charter & {$[.2, .4)$} & 0.20754717 & 0.12264151 & 0.2803738 \\
\hline ELA & 4-7 years in district & Charter & {$[.4, .6)$} & 0.22115385 & 0.12121212 & 0.2843137 \\
\hline ELA & 4-7 years in district & Charter & {$[.6, .8)$} & 0.18867925 & 0.13131313 & 0.2980769 \\
\hline ELA & 4-7 years in district & Charter & {$[.8,1]$} & 0.28971963 & 0.20406182 & 0.3555556 \\
\hline ELA & 4-7 years in district & TPS & {$[0, .2)$} & 0.14936248 & 0.13623953 & 0.1639723 \\
\hline ELA & 4-7 years in district & TPS & {$[.2, .4)$} & 0.11810306 & 0.10149332 & 0.1299794 \\
\hline ELA & 4-7 years in district & TPS & {$[.4, .6)$} & 0.11577028 & 0.10074873 & 0.1282288 \\
\hline ELA & 4-7 years in district & TPS & {$[.6, .8)$} & 0.11035112 & 0.09341106 & 0.1209539 \\
\hline ELA & 4-7 years in district & TPS & {$[.8,1]$} & 0.11202186 & 0.10632447 & 0.1322213 \\
\hline Math & $<4$ years in district & Charter & {$[0, .2)$} & 0.34883721 & 0.27981651 & 0.3970659 \\
\hline Math & $<4$ years in district & Charter & {$[.2, .4)$} & 0.23222749 & 0.16589862 & 0.2883721 \\
\hline Math & $<4$ years in district & Charter & {$[.4, .6)$} & 0.19718310 & 0.15714286 & 0.2745098 \\
\hline Math & $<4$ years in district & Charter & {$[.6, .8)$} & 0.22748815 & 0.17412935 & 0.2918660 \\
\hline Math & $<4$ years in district & Charter & {$[.8,1]$} & 0.26976744 & 0.21078212 & 0.3254717 \\
\hline Math & $<4$ years in district & TPS & {$[0, .2)$} & 0.21497326 & 0.20270857 & 0.2380250 \\
\hline Math & $<4$ years in district & TPS & {$[.2, .4)$} & 0.17291221 & 0.14846114 & 0.1841392 \\
\hline Math & $<4$ years in district & TPS & {$[.4, .6)$} & 0.15854312 & 0.13080504 & 0.1644356 \\
\hline Math & $<4$ years in district & TPS & {$[.6, .8)$} & 0.13650964 & 0.12334708 & 0.1568544 \\
\hline Math & $<4$ years in district & TPS & {$[.8,1]$} & 0.14018192 & 0.13448931 & 0.1647825 \\
\hline Math & 4-7 years in district & Charter & {$[0, .2)$} & 0.23008850 & 0.14782609 & 0.2906294 \\
\hline Math & 4-7 years in district & Charter & {$[.2, .4)$} & 0.16363636 & 0.09734513 & 0.2545455 \\
\hline Math & 4-7 years in district & Charter & {$[.4, .6)$} & 0.16666667 & 0.11818182 & 0.2800000 \\
\hline Math & 4-7 years in district & Charter & {$[.6, .8)$} & 0.21818182 & 0.12871287 & 0.2871287 \\
\hline Math & 4-7 years in district & Charter & {$[.8,1]$} & 0.25000000 & 0.17094017 & 0.3157895 \\
\hline Math & 4-7 years in district & TPS & {$[0, .2)$} & 0.14700461 & 0.13257298 & 0.1597431 \\
\hline Math & 4-7 years in district & TPS & {$[.2, .4)$} & 0.10977860 & 0.10000000 & 0.1282169 \\
\hline Math & 4-7 years in district & TPS & {$[.4, .6)$} & 0.11490540 & 0.09414885 & 0.1213843 \\
\hline Math & 4-7 years in district & TPS & {$[.6, .8)$} & 0.09870849 & 0.08531638 & 0.1114232 \\
\hline Math & 4-7 years in district & TPS & {$[.8,1]$} & 0.10829493 & 0.10092980 & 0.1258709 \\
\hline
\end{tabular}


TABLE E.2: Numerical Values for Figure 2

\begin{tabular}{|c|c|c|c|c|c|c|}
\hline Subject & Tenure category & School type & School quality quintile & Attrition probability & $95 \%$ CI lower bound & $95 \%$ CI upper bound \\
\hline ELA & $<4$ years in district & Charter & {$[0, .2)$} & 0.25339367 & 0.21255435 & 0.3179933 \\
\hline ELA & $<4$ years in district & Charter & {$[.2, .4)$} & 0.27227723 & 0.19395672 & 0.3230769 \\
\hline ELA & $<4$ years in district & Charter & {$[.4, .6)$} & 0.18787879 & 0.14649360 & 0.2757170 \\
\hline ELA & $<4$ years in district & Charter & {$[.6, .8)$} & 0.23287671 & 0.13953488 & 0.2702703 \\
\hline ELA & $<4$ years in district & Charter & {$[.8,1]$} & 0.20247934 & 0.17594232 & 0.2702703 \\
\hline ELA & $<4$ years in district & TPS & {$[0, .2)$} & 0.22936945 & 0.21194203 & 0.2406952 \\
\hline ELA & $<4$ years in district & TPS & {$[.2, .4)$} & 0.14984709 & 0.13809919 & 0.1704266 \\
\hline ELA & $<4$ years in district & TPS & {$[.4, .6)$} & 0.15852923 & 0.13671832 & 0.1716982 \\
\hline ELA & $<4$ years in district & TPS & {$[.6, .8)$} & 0.14584544 & 0.13227812 & 0.1655798 \\
\hline ELA & $<4$ years in district & TPS & {$[.8,1]$} & 0.13282621 & 0.12023427 & 0.1503380 \\
\hline ELA & 4-7 years in district & Charter & {$[0, .2)$} & 0.23529412 & 0.18784091 & 0.3333333 \\
\hline ELA & 4-7 years in district & Charter & {$[.2, .4)$} & 0.21212121 & 0.12500000 & 0.3008202 \\
\hline ELA & 4-7 years in district & Charter & {$[.4, .6)$} & 0.24324324 & 0.15713105 & 0.3149606 \\
\hline ELA & 4-7 years in district & Charter & {$[.6, .8)$} & 0.17045455 & 0.11811024 & 0.2800000 \\
\hline ELA & 4-7 years in district & Charter & {$[.8,1]$} & 0.21875000 & 0.13888889 & 0.2842105 \\
\hline ELA & 4-7 years in district & TPS & {$[0, .2)$} & 0.16296625 & 0.15227484 & 0.1791491 \\
\hline ELA & 4-7 years in district & TPS & {$[.2, .4)$} & 0.12452107 & 0.10767032 & 0.1354379 \\
\hline ELA & 4-7 years in district & TPS & {$[.4, .6)$} & 0.11184211 & 0.09747630 & 0.1246581 \\
\hline ELA & 4-7 years in district & TPS & {$[.6, .8)$} & 0.10572302 & 0.09506159 & 0.1210017 \\
\hline ELA & 4-7 years in district & TPS & {$[.8,1]$} & 0.10022573 & 0.08887766 & 0.1113618 \\
\hline Math & $<4$ years in district & Charter & {$[0, .2)$} & 0.34042553 & 0.25609756 & 0.3937008 \\
\hline Math & $<4$ years in district & Charter & {$[.2, .4)$} & 0.19634703 & 0.15568580 & 0.2719729 \\
\hline Math & $<4$ years in district & Charter & {$[.4, .6)$} & 0.26530612 & 0.20376660 & 0.3231441 \\
\hline Math & $<4$ years in district & Charter & {$[.6, .8)$} & 0.26842105 & 0.19534884 & 0.3212670 \\
\hline Math & $<4$ years in district & Charter & {$[.8,1]$} & 0.24074074 & 0.20138889 & 0.3000000 \\
\hline Math & $<4$ years in district & TPS & {$[0, .2)$} & 0.21218962 & 0.19749029 & 0.2278173 \\
\hline Math & $<4$ years in district & TPS & {$[.2, .4)$} & 0.17111460 & 0.14885624 & 0.1831243 \\
\hline Math & $<4$ years in district & TPS & {$[.4, .6)$} & 0.14120879 & 0.13148205 & 0.1664842 \\
\hline Math & $<4$ years in district & TPS & {$[.6, .8)$} & 0.14978448 & 0.12886829 & 0.1623149 \\
\hline Math & $<4$ years in district & TPS & {$[.8,1]$} & 0.13376623 & 0.12094150 & 0.1528349 \\
\hline Math & 4-7 years in district & Charter & {$[0, .2)$} & 0.20588235 & 0.14864865 & 0.2906977 \\
\hline Math & 4-7 years in district & Charter & {$[.2, .4)$} & 0.18320611 & 0.11214148 & 0.2429907 \\
\hline Math & 4-7 years in district & Charter & {$[.4, .6)$} & 0.15555556 & 0.10294118 & 0.2377440 \\
\hline Math & 4-7 years in district & Charter & {$[.6, .8)$} & 0.23913043 & 0.15238095 & 0.3207547 \\
\hline Math & 4-7 years in district & Charter & {$[.8,1]$} & 0.27956989 & 0.19767442 & 0.3658537 \\
\hline Math & 4-7 years in district & TPS & {$[0, .2)$} & 0.14398422 & 0.13197727 & 0.1590115 \\
\hline Math & 4-7 years in district & TPS & {$[.2, .4)$} & 0.10468972 & 0.09476523 & 0.1225403 \\
\hline Math & 4-7 years in district & TPS & {$[.4, .6)$} & 0.11154177 & 0.09362443 & 0.1216353 \\
\hline Math & 4-7 years in district & TPS & {$[.6, .8)$} & 0.12043302 & 0.10433657 & 0.1323197 \\
\hline Math & 4-7 years in district & TPS & {$[.8,1]$} & 0.09976905 & 0.09086768 & 0.1149865 \\
\hline
\end{tabular}


TABLE E.3: Numerical Values for Figure 3

\begin{tabular}{|c|c|c|c|c|c|c|}
\hline School quality & Tenure category & School type & Value-added quintile & Attrition probability & 95\% CI lower bound & 95\% CI upper bound \\
\hline Bottom $40 \%$ of Schools & $<4$ years in district & Charter & {$[0, .2)$} & 0.3361668 & 0.24257826 & 0.4131157 \\
\hline Bottom $40 \%$ of Schools & $<4$ years in district & Charter & {$[.2, .4)$} & 0.2230523 & 0.14578366 & 0.3118399 \\
\hline Bottom $40 \%$ of Schools & $<4$ years in district & Charter & {$[.4, .6)$} & 0.1719640 & 0.12388039 & 0.2732490 \\
\hline Bottom $40 \%$ of Schools & $<4$ years in district & Charter & {$[.6, .8)$} & 0.2251834 & 0.13778035 & 0.2980925 \\
\hline Bottom $40 \%$ of Schools & $<4$ years in district & Charter & {$[.8,1]$} & 0.3166822 & 0.19905031 & 0.3730719 \\
\hline Bottom $40 \%$ of Schools & $<4$ years in district & TPS & {$[0, .2)$} & 0.2384832 & 0.22023979 & 0.2659158 \\
\hline Bottom $40 \%$ of Schools & $<4$ years in district & TPS & {$[.2, .4)$} & 0.2109730 & 0.17661911 & 0.2254182 \\
\hline Bottom $40 \%$ of Schools & $<4$ years in district & TPS & {$[.4, .6)$} & 0.1982241 & 0.16056257 & 0.2073625 \\
\hline Bottom $40 \%$ of Schools & $<4$ years in district & TPS & {$[.6, .8)$} & 0.1724266 & 0.15035366 & 0.1967527 \\
\hline Bottom $40 \%$ of Schools & $<4$ years in district & TPS & {$[.8,1]$} & 0.1505303 & 0.14240680 & 0.1821939 \\
\hline Bottom $40 \%$ of Schools & 4-7 years in district & Charter & {$[0, .2)$} & 0.2110632 & 0.11014593 & 0.3257887 \\
\hline Bottom $40 \%$ of Schools & 4-7 years in district & Charter & {$[.2, .4)$} & 0.2056434 & 0.08950503 & 0.3000585 \\
\hline Bottom $40 \%$ of Schools & 4-7 years in district & Charter & {$[.4, .6)$} & 0.1794898 & 0.09484445 & 0.2928583 \\
\hline Bottom $40 \%$ of Schools & 4-7 years in district & Charter & {$[.6, .8)$} & 0.2151240 & 0.10343502 & 0.3209980 \\
\hline Bottom $40 \%$ of Schools & 4-7 years in district & Charter & {$[.8,1]$} & 0.3021265 & 0.18729407 & 0.4050250 \\
\hline Bottom $40 \%$ of Schools & 4-7 years in district & TPS & {$[0, .2)$} & 0.1729935 & 0.15489533 & 0.1936218 \\
\hline Bottom $40 \%$ of Schools & 4-7 years in district & TPS & {$[.2, .4)$} & 0.1370653 & 0.10995171 & 0.1509764 \\
\hline Bottom $40 \%$ of Schools & 4-7 years in district & TPS & {$[.4, .6)$} & 0.1216003 & 0.10685712 & 0.1461386 \\
\hline Bottom $40 \%$ of Schools & 4-7 years in district & TPS & {$[.6, .8)$} & 0.1217824 & 0.10113559 & 0.1394167 \\
\hline Bottom $40 \%$ of Schools & 4-7 years in district & TPS & {$[.8,1]$} & 0.1268706 & 0.11513698 & 0.1499132 \\
\hline Upper $40 \%$ of Schools & $<4$ years in district & Charter & {$[0, .2)$} & 0.2806435 & 0.20193521 & 0.3586323 \\
\hline Upper $40 \%$ of Schools & $<4$ years in district & Charter & {$[.2, .4)$} & 0.2384757 & 0.14603233 & 0.3087720 \\
\hline Upper $40 \%$ of Schools & $<4$ years in district & Charter & {$[.4, .6)$} & 0.1936914 & 0.12624015 & 0.2921061 \\
\hline Upper $40 \%$ of Schools & $<4$ years in district & Charter & {$[.6, .8)$} & 0.2117674 & 0.11281092 & 0.2708503 \\
\hline Upper $40 \%$ of Schools & $<4$ years in district & Charter & {$[.8,1]$} & 0.1692379 & 0.12467304 & 0.2599871 \\
\hline Upper $40 \%$ of Schools & $<4$ years in district & TPS & {$[0, .2)$} & 0.1561269 & 0.13717829 & 0.1854847 \\
\hline Upper $40 \%$ of Schools & $<4$ years in district & TPS & {$[.2, .4)$} & 0.1470947 & 0.11822039 & 0.1642796 \\
\hline Upper $40 \%$ of Schools & $<4$ years in district & TPS & {$[.4, .6)$} & 0.1490780 & 0.12265451 & 0.1680761 \\
\hline Upper $40 \%$ of Schools & $<4$ years in district & TPS & {$[.6, .8)$} & 0.1362841 & 0.11258744 & 0.1570624 \\
\hline Upper $40 \%$ of Schools & $<4$ years in district & TPS & {$[.8,1]$} & 0.1235303 & 0.11359632 & 0.1573974 \\
\hline Upper $40 \%$ of Schools & 4-7 years in district & Charter & {$[0, .2)$} & 0.2081211 & 0.12982300 & 0.3468343 \\
\hline Upper $40 \%$ of Schools & 4-7 years in district & Charter & {$[.2, .4)$} & 0.2543216 & 0.11598033 & 0.3614878 \\
\hline Upper $40 \%$ of Schools & 4-7 years in district & Charter & {$[.4, .6)$} & 0.3161887 & 0.09867570 & 0.3547974 \\
\hline Upper $40 \%$ of Schools & 4-7 years in district & Charter & {$[.6, .8)$} & 0.1267790 & 0.10549588 & 0.3328921 \\
\hline Upper $40 \%$ of Schools & 4-7 years in district & Charter & {$[.8,1]$} & 0.2797274 & 0.17568775 & 0.3668092 \\
\hline Upper $40 \%$ of Schools & 4-7 years in district & TPS & {$[0, .2)$} & 0.1213341 & 0.10640646 & 0.1427163 \\
\hline Upper $40 \%$ of Schools & 4-7 years in district & TPS & {$[.2, .4)$} & 0.1050968 & 0.08805483 & 0.1240732 \\
\hline Upper $40 \%$ of Schools & 4-7 years in district & TPS & {$[.4, .6)$} & 0.1114361 & 0.09067420 & 0.1255328 \\
\hline Upper $40 \%$ of Schools & 4-7 years in district & TPS & {$[.6, .8)$} & 0.1084607 & 0.08568049 & 0.1213849 \\
\hline Upper $40 \%$ of Schools & 4-7 years in district & TPS & {$[.8,1]$} & 0.1003449 & 0.09205691 & 0.1275815 \\
\hline
\end{tabular}


TABLE E.4: Numerical Values for Figure 4

\begin{tabular}{ccccc}
\hline \hline Attrition type & School type & Years in district & Probability & Standard error \\
\hline Exit & Charter & 1 & 0.11773940 & 0.009033273 \\
Exit & Charter & 2 & 0.08389262 & 0.009277038 \\
Exit & Charter & 3 & 0.09629630 & 0.011362866 \\
Exit & Charter & 4 & 0.10351967 & 0.013875809 \\
Exit & Charter & 5 & 0.10724638 & 0.016683144 \\
Exit & Charter & 6 & 0.09505703 & 0.018119745 \\
Exit & Charter & 7 & 0.07246377 & 0.018063100 \\
Exit & TPS & 1 & 0.07458256 & 0.002530453 \\
Exit & TPS & 2 & 0.06203641 & 0.002557376 \\
Exit & TPS & 3 & 0.06097240 & 0.002743103 \\
Exit & TPS & 4 & 0.05006568 & 0.002634945 \\
Exit & TPS & 5 & 0.05128205 & 0.002801273 \\
Exit & TPS & 6 & 0.04754575 & 0.002783226 \\
Exit & TPS & 7 & 0.04859813 & 0.002803209 \\
Move & Charter & 1 & 0.17189953 & 0.010574617 \\
Move & Charter & 2 & 0.12751678 & 0.011161858 \\
Move & Charter & 3 & 0.12444444 & 0.012714511 \\
Move & Charter & 4 & 0.12215321 & 0.014915516 \\
Move & Charter & 5 & 0.11014493 & 0.016879620 \\
Move & Charter & 6 & 0.09505703 & 0.018119745 \\
Move & Charter & 7 & 0.07246377 & 0.018063100 \\
Move & TPS & 1 & 0.20166976 & 0.003864759 \\
Move & TPS & 2 & 0.14014385 & 0.003680257 \\
Move & TPS & 3 & 0.11524310 & 0.003660628 \\
Move & TPS & 4 & 0.09589841 & 0.003557698 \\
Move & TPS & 5 & 0.08498629 & 0.003541542 \\
Move & TPS & 6 & 0.08192235 & 0.003586836 \\
Move & TPS & 7 & 0.06677995 & 0.003254459 \\
\hline & & & & \\
\hline
\end{tabular}


TABLE E.5: Numerical Values for Figure 5

\begin{tabular}{|c|c|c|c|c|c|c|}
\hline Attrition category & Tenure category & School type & Value-added quintile & Attrition probability & $95 \%$ CI lower bound & $95 \%$ CI upper bound \\
\hline Exit & $<4$ years in district & Charter & {$[0, .2)$} & 0.19069767 & 0.13485689 & 0.23214286 \\
\hline Exit & $<4$ years in district & Charter & {$[.2, .4)$} & 0.12796209 & 0.08530806 & 0.18357488 \\
\hline Exit & $<4$ years in district & Charter & {$[.4, .6)$} & 0.11737089 & 0.07804878 & 0.17158348 \\
\hline Exit & $<4$ years in district & Charter & {$[.6, .8)$} & 0.12322275 & 0.07582938 & 0.16822879 \\
\hline Exit & $<4$ years in district & Charter & {$[.8,1]$} & 0.13488372 & 0.09458787 & 0.18433180 \\
\hline Exit & $<4$ years in district & TPS & {$[0, .2)$} & 0.09144385 & 0.08119658 & 0.10576465 \\
\hline Exit & $<4$ years in district & TPS & {$[.2, .4)$} & 0.07387580 & 0.05959400 & 0.08441629 \\
\hline Exit & $<4$ years in district & TPS & {$[.4, .6)$} & 0.06748795 & 0.05113891 & 0.07413333 \\
\hline Exit & $<4$ years in district & TPS & {$[.6, .8)$} & 0.06049251 & 0.05029396 & 0.07342560 \\
\hline Exit & $<4$ years in district & TPS & {$[.8,1]$} & 0.05885500 & 0.05311159 & 0.07393416 \\
\hline Exit & 4-7 years in district & Charter & {$[0, .2)$} & 0.14159292 & 0.07692308 & 0.19533012 \\
\hline Exit & 4-7 years in district & Charter & {$[.2, .4)$} & 0.12727273 & 0.05217391 & 0.18181818 \\
\hline Exit & 4-7 years in district & Charter & {$[.4, .6)$} & 0.09259259 & 0.05714286 & 0.19000000 \\
\hline Exit & 4-7 years in district & Charter & {$[.6, .8)$} & 0.10909091 & 0.04716981 & 0.17213115 \\
\hline Exit & 4-7 years in district & Charter & {$[.8,1]$} & 0.09821429 & 0.04854369 & 0.15517241 \\
\hline Exit & 4-7 years in district & TPS & {$[0, .2)$} & 0.06728111 & 0.05866178 & 0.07858556 \\
\hline Exit & 4-7 years in district & TPS & {$[.2, .4)$} & 0.06088561 & 0.04819841 & 0.06874978 \\
\hline Exit & 4-7 years in district & TPS & {$[.4, .6)$} & 0.05353023 & 0.04403670 & 0.06391848 \\
\hline Exit & 4-7 years in district & TPS & {$[.6, .8)$} & 0.05027675 & 0.03992249 & 0.05900975 \\
\hline Exit & 4-7 years in district & TPS & {$[.8,1]$} & 0.05023041 & 0.04385133 & 0.06129032 \\
\hline Move & $<4$ years in district & Charter & {$[0, .2)$} & 0.15813953 & 0.11267606 & 0.20000000 \\
\hline Move & $<4$ years in district & Charter & {$[.2, .4)$} & 0.10426540 & 0.05392157 & 0.13658537 \\
\hline Move & $<4$ years in district & Charter & {$[.4, .6)$} & 0.07981221 & 0.05213270 & 0.13526570 \\
\hline Move & $<4$ years in district & Charter & {$[.6, .8)$} & 0.10426540 & 0.07042254 & 0.15668203 \\
\hline Move & $<4$ years in district & Charter & {$[.8,1]$} & 0.13488372 & 0.08920188 & 0.17347405 \\
\hline Move & $<4$ years in district & TPS & {$[0, .2)$} & 0.12352941 & 0.11288605 & 0.14136873 \\
\hline Move & $<4$ years in district & TPS & {$[.2, .4)$} & 0.09903640 & 0.08057555 & 0.10857763 \\
\hline Move & $<4$ years in district & TPS & {$[.4, .6)$} & 0.09105517 & 0.07189189 & 0.09837925 \\
\hline Move & $<4$ years in district & TPS & {$[.6, .8)$} & 0.07601713 & 0.06571695 & 0.09172901 \\
\hline Move & $<4$ years in district & TPS & {$[.8,1]$} & 0.08132691 & 0.07425214 & 0.09861407 \\
\hline Move & 4-7 years in district & Charter & {$[0, .2)$} & 0.08849558 & 0.03703704 & 0.13559322 \\
\hline Move & 4-7 years in district & Charter & {$[.2, .4)$} & 0.03636364 & 0.01769912 & 0.11206897 \\
\hline Move & 4-7 years in district & Charter & {$[.4, .6)$} & 0.07407407 & 0.02752294 & 0.13274336 \\
\hline Move & 4-7 years in district & Charter & {$[.6, .8)$} & 0.10909091 & 0.04504505 & 0.16071429 \\
\hline Move & 4-7 years in district & Charter & {$[.8,1]$} & 0.15178571 & 0.08771930 & 0.20412801 \\
\hline Move & 4-7 years in district & TPS & {$[0, .2)$} & 0.07972350 & 0.06739366 & 0.08762195 \\
\hline Move & 4-7 years in district & TPS & {$[.2, .4)$} & 0.04889299 & 0.04577985 & 0.06568842 \\
\hline Move & 4-7 years in district & TPS & {$[.4, .6)$} & 0.06137517 & 0.04426340 & 0.06382979 \\
\hline Move & 4-7 years in district & TPS & {$[.6, .8)$} & 0.04843173 & 0.03977196 & 0.05885079 \\
\hline Move & 4-7 years in district & TPS & {$[.8,1]$} & 0.05806452 & 0.05162670 & 0.07001972 \\
\hline
\end{tabular}


TABLE E.6: Numerical Values for Figure 7

\begin{tabular}{|c|c|c|}
\hline Event time & Coefficient estimate & Standard error \\
\hline$t=-7$ & 0.074729034 & 0.04380183 \\
\hline$t=-6$ & 0.035163030 & 0.02528069 \\
\hline$t=-5$ & 0.003771686 & 0.02019910 \\
\hline$t=-4$ & 0.009244287 & 0.01556079 \\
\hline$t=-3$ & 0.001703819 & 0.01250051 \\
\hline$t=-2$ & -0.001482254 & 0.01008987 \\
\hline$t=0$ & 0.112369351 & 0.01164143 \\
\hline$t=1$ & 0.158507355 & 0.01688254 \\
\hline$t=2$ & 0.157776160 & 0.02097686 \\
\hline$t=3$ & 0.149167993 & 0.02458032 \\
\hline$t=4$ & 0.166976580 & 0.02998731 \\
\hline$t=5$ & 0.155666158 & 0.03553352 \\
\hline$t=6$ & 0.132833788 & 0.04211308 \\
\hline$t=7$ & 0.207276511 & 0.05345308 \\
\hline $\mathrm{t}=8$ & 0.203385442 & 0.06391623 \\
\hline
\end{tabular}

